\title{
Transcriptome analysis reveals mechanism of early ripening in Kyoho grape with hydrogen peroxide treatment
}

\author{
Da-Long Guo ${ }^{1,2^{*}}$, Zhen-Guang Wang ${ }^{1,2}$, Mao-Song Pei ${ }^{1,2}$, Li-Li Guo ${ }^{2}$ and Yi-He Yu ${ }^{1,2}$
}

\begin{abstract}
Background: In a previous study, the early ripening of Kyoho grape following $\mathrm{H}_{2} \mathrm{O}_{2}$ treatment was explored at the physiological level, but the mechanism by which $\mathrm{H}_{2} \mathrm{O}_{2}$ promotes ripening at the molecular level is unclear. To reveal the molecular mechanism, RNA-sequencing analysis was conducted on the different developmental stages of Kyoho berry treated with $\mathrm{H}_{2} \mathrm{O}_{2}$.

Results: In the comparison of treatment and control groups, 406 genes were up-regulated and 683 were downregulated. Time course sequencing (TCseq) analysis showed that the expression patterns of most of the genes were similar between the treatment and control, except for some genes related to chlorophyll binding and photosynthesis. Differential expression analysis and the weighted gene co-expression network were used to screen significantly differentially expressed genes and hub genes associated with oxidative stress (heat shock protein, HSP), cell wall deacetylation (GDSL esterase/lipase, GDSL), cell wall degradation (xyloglucan endotransglucosylase/ hydrolase, XTH), and photosynthesis (chlorophyll $a-b$ binding protein, CAB1). Gene expression was verified with RT-qPCR, and the results were largely consistent with those of RNA sequencing.
\end{abstract}

Conclusions: The RNA-sequencing analysis indicated that $\mathrm{H}_{2} \mathrm{O}_{2}$ treatment promoted the early ripening of Kyoho berry by affecting the expression levels of HSP, GDSL, XTH, and CAB1 and-photosynthesis- pathways.

Keywords: Early ripening, Grape, Kyoho, Hydrogen peroxide, RNA sequencing

\section{Background}

Grape (Vitis vinifera L.) is one of the oldest and most important fruit crops and is cultivated worldwide [1] Globally, grape berries, raisins, and wine are economically important commodities [2]. The grape berry ripening process is complicated and highly coordinated [3], with many physiological changes [4], including cell division and elongation, change in skin color, berry softening, increasing sugar content, decreasing organic acid and tannin contents, and the accumulation of aromas [5]. In addition,

\footnotetext{
* Correspondence: guodalong@haust.edu.cn

${ }^{1}$ College of Forestry, Henan University of Science and Technology, Luoyang 471023, Henan Province, China

${ }^{2}$ Henan Engineering Technology Research Center of Quality Regulation and Controlling of Horticultural Plants, Luoyang 471023, Henan Province, China
}

fruit ripening is an oxidative process, in which the redox homeostasis changes in cells [6]. Reactive oxygen species (ROS) play a key role in fruit ripening by regulating antioxidant systems $[7,8]$. Reactive oxygen species initiate senescence for fruit ripening through the accumulation of $\mathrm{O}_{2}$ ? and $\mathrm{H}_{2} \mathrm{O}_{2}[9,10]$.

Hydrogen peroxide $\left(\mathrm{H}_{2} \mathrm{O}_{2}\right)$ is an oxidant that can increase oxidative damage, cause metabolic dysfunction, and damage cell integrity [11]. At low concentrations, $\mathrm{H}_{2} \mathrm{O}_{2}$ can be used as signaling molecules that play key roles in biotic and abiotic stress responses, hormonal responses, growth and development, and fruit ripening [12]. However, when accumulated in plant tissues or fruits, $\mathrm{H}_{2} \mathrm{O}_{2}$ can promote programmed cell death [13]. Hydrogen peroxide not only functions in programmed

C The Author(s). 2020 Open Access This article is licensed under a Creative Commons Attribution 4.0 International License, which permits use, sharing, adaptation, distribution and reproduction in any medium or format, as long as you give appropriate credit to the original author(s) and the source, provide a link to the Creative Commons licence, and indicate if changes were made. The images or other third party material in this article are included in the article's Creative Commons licence, unless indicated otherwise in a credit line to the material. If material is not included in the article's Creative Commons licence and your intended use is not permitted by statutory regulation or exceeds the permitted use, you will need to obtain permission directly from the copyright holder. To view a copy of this licence, visit http://creativecommons.org/licenses/by/4.0/. The Creative Commons Public Domain Dedication waiver (http://creativecommons.org/publicdomain/zero/1.0/) applies to the data made available in this article, unless otherwise stated in a credit line to the data. 
cell death [14] but also is involved in the ripening of tomato [9] and pear [15]. Pilati et al. [16] observed a distinct oxidative burst during grape ripening and the rapid accumulation of $\mathrm{H}_{2} \mathrm{O}_{2}$, which was associated with grape softening and ripening. In addition, $\mathrm{H}_{2} \mathrm{O}_{2}$ is involved in the degradation of cell membranes and cell walls in tomato, thereby causing tomato softening and ripening [17]. Compared with a mutant (rin) tomato, the activity of ascorbate peroxidase decreased in wild-type tomato, and because $\mathrm{H}_{2} \mathrm{O}_{2}$ could not be cleared, it accumulated, thereby intensifying the degradation of cell walls and accelerating the softening and ripening of tomato [18].

The grape cultivar Fengzao is a bud mutant of Kyoho grape that has the distinct character of early ripening [19], maturing $30 \mathrm{~d}$ earlier than Kyoho. The comparison of Fengzao and Kyoho berries at the transcriptional level showed that ROS metabolism-related genes were significantly differentially expressed [20]. Differences were also revealed between the two cultivars in ROS metabolism at the physiological level [21]. Furthermore, $\mathrm{H}_{2} \mathrm{O}_{2}$, as an exogenous ROS, was sprayed on young Kyoho berries, which promoted earlier ripening, $20 \mathrm{~d}$ earlier than the control [10]. The treatment of hydrogen peroxide is not spraying on the whole plant, we just sprayed on the berry cluster. And there is not any obvious effect the growth and development of whole plant after the treatment. Although the exogenous $\mathrm{H}_{2} \mathrm{O}_{2}$ promoted berry ripening, the regulatory mechanism of this process at the molecular level is unclear.

In this study, to determine the influences of $\mathrm{H}_{2} \mathrm{O}_{2}$ treatment in promoting the early ripening of Kyoho grape, transcriptomic analysis was used to investigate and identify differentially regulated genes after $\mathrm{H}_{2} \mathrm{O}_{2}$ treatment. The results will provide the basis for the further exploration of the effects of $\mathrm{H}_{2} \mathrm{O}_{2}$ treatment on early ripening of grape berries.

\section{Results}

\section{Overview of RNA-sequencing analysis}

The transcriptome using total mRNA sequencing data was generated on an Illumina HiSeq 2500 platform (Illumina, San Diego, CA, USA). Approximately 46 million raw reads were obtained for each stage after the filtering of the raw reads. The $\mathrm{Q}_{30}$ values averaged approximately $94 \%$. The clean reads were mapped to the grape reference genome (ftp://ftp.ensemblgenomes.org/pub/plants/ release-38/fasta/vitis_vinifera). The mapping rate of the 23 samples to the grape reference genome was approximately 90\% (Supplemental Table S1).

To survey the distribution of gene numbers, a Venn diagram was prepared in the VennDiagram package (Fig. 1). A total of 40,568 genes were identified in the control groups, of which 10,154 were in stage K1, 10,073 in stage K2, 10,206 in stage $\mathrm{K} 3$, and 10,135 in stage K4, and 9035 genes were commonly expressed in all the control groups (Fig. 1a). A total of 40,591 genes were expressed in the treatment groups, of which 10,153 were in stage $\mathrm{H1}, 10,157$ in stage $\mathrm{H} 2,10,147$ in stage $H 3$, and 10,134 in stage $H 4$, and 3922 genes were commonly expressed in all the treatment groups (Fig. 1b). The K21 sample was eliminated from the following analysis due to the poor repetition.

\section{Overall expression patterns between the control and the treatment}

To investigate the gene expression profiles of both the control and treatment, the expression patterns were

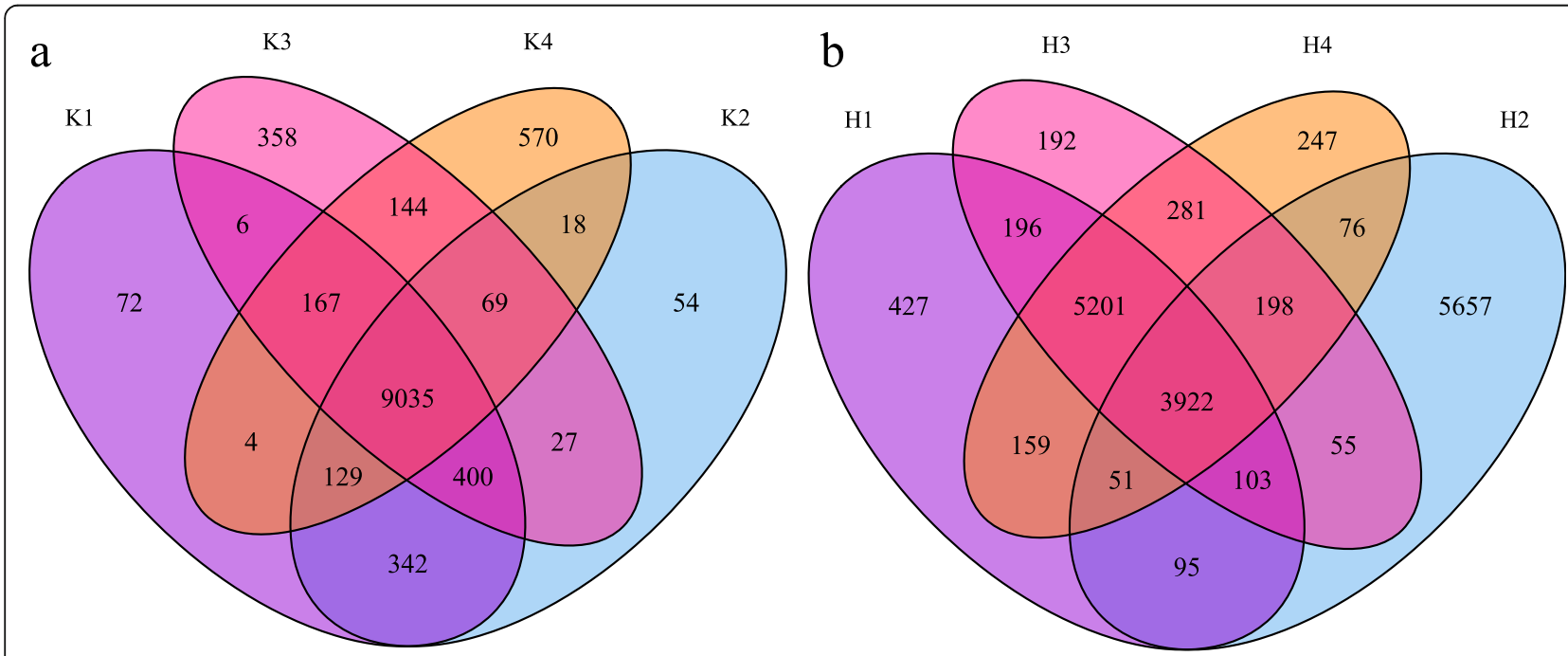

Fig. 1 The number of expressed genes at difference sampling stages and the demonstration of the principal component analysis. a Venn diagram showed the number of the expressed genes in the control group; $\mathbf{b}$ Venn diagram showed the number of the expressed genes in the treatment group 
compared using the TCseq clustering method. The division of clusters was determined using the vegan package. The highest Calinski criterion value was eight, indicating that the optimal number of clusters was eight. Hence, the gene expression patterns of the control and treatment groups were divided into eight categories (Supplemental Fig. S1). In the comparison of the gene expression profiles between the control and the treatment, the gene expression profiles of most clusters were similar (Fig. 2). However, the expression patterns between the control and the treatment in cluster 1 (4741 genes) and cluster 5 (4009 genes) were different. In cluster 1 , the expression of genes decreased rapidly from the $\mathrm{H} 1$ to $\mathrm{H} 2$ stage. However, the expression patterns of genes were steady from the $\mathrm{K} 1$ to $\mathrm{K} 4$ stages. In cluster 5 , the gene expression was similar in $\mathrm{H} 1$ and $\mathrm{H} 2$ stages and in $\mathrm{K} 1$ and $\mathrm{K} 2$ stages. The expression of genes increased rapidly from the $\mathrm{H} 3$ to $\mathrm{H} 4$ stage, but the increase was not as great from the $\mathrm{K} 3$ to $\mathrm{K} 4$ stage.

To further identify the functions of the genes in clusters 1 and 5, GO (Gene Ontology) and KEGG (Kyoto Encyclopedia of Genes and Genomes) enrichment analyses were performed (Fig. 3a and b) with ClusterProfiler. The GO enrichment analysis generated 22 top GO terms (Fig. 3a). Eight of the 22 top GO terms (e.g., structural constituent of ribosome, structural molecule activity, pigment binding, chlorophyll binding) were associated with cluster 1 . The other 14 most enriched GO terms (e.g., nuclease activity, enzyme binding, endonuclease activity) were associated with cluster 5 . The KEGG pathway analysis revealed the enrichment of nine pathways (Fig. 3b). Five of the nine top KEGG pathways (ribosome, photosynthesis, photosynthesis-antenna proteins, phagosome, and oxidative phosphorylation) were associated with cluster 1 . The other four pathways (spliceosome, mRNA surveillance pathway, glycolysis/gluconeogenesis, and flavone and flavonol biosynthesis) were associated with cluster 5 . Notably, the GO terms pigment binding and chlorophyll binding and the KEGG pathways photosynthesis-antenna proteins, photosynthesis, and oxidative phosphorylation are consistent with previous results [22]. Therefore, the genes associated with these GO terms and KEGG pathways were the focus of further analysis.

\section{Analysis of differentially expressed genes}

In this study, the differentially expressed genes (DEGs) were identified using DESeq2. A total of 1089 DEGs were identified in the comparisons of the treatment and control groups. Some DEGs were selected on the basis of the rank of the fold changes of up- or down-regulation and are listed in Table 1. To further explore the expression of DEGs in the control and treatment groups, a heat map was constructed (Fig. 4) with the pheatmap package. Figure 4 reveals that the DEGs were distributed in the comparisons of $\mathrm{H} 1$ and $\mathrm{K} 1$ (four up-regulated and nine down-regulated), H2 and K2 (34 up-regulated and four down-regulated), $\mathrm{H} 3$ and $\mathrm{K} 3$ (14 up-regulated and 13 down-regulated), and $\mathrm{H} 4$ and K4 (354 up-regulated and 657 downregulated) stages (the gene IDs are shown Supplemental Table S2). To identify the DEGs in common, a Venn diagram was constructed; however, the treatment and the control did not share any of the same genes (Fig. 4e).

To further investigate the molecular mechanisms involving the DEGs in the treatment and the control, the DEGs were analyzed by GO and KEGG enrichment analyses (Fig. 5). The GO enrichment analysis revealed four top GO terms, including pigment tetrapyrrole binding, pigment binding, chlorophyll binding, and antioxidant

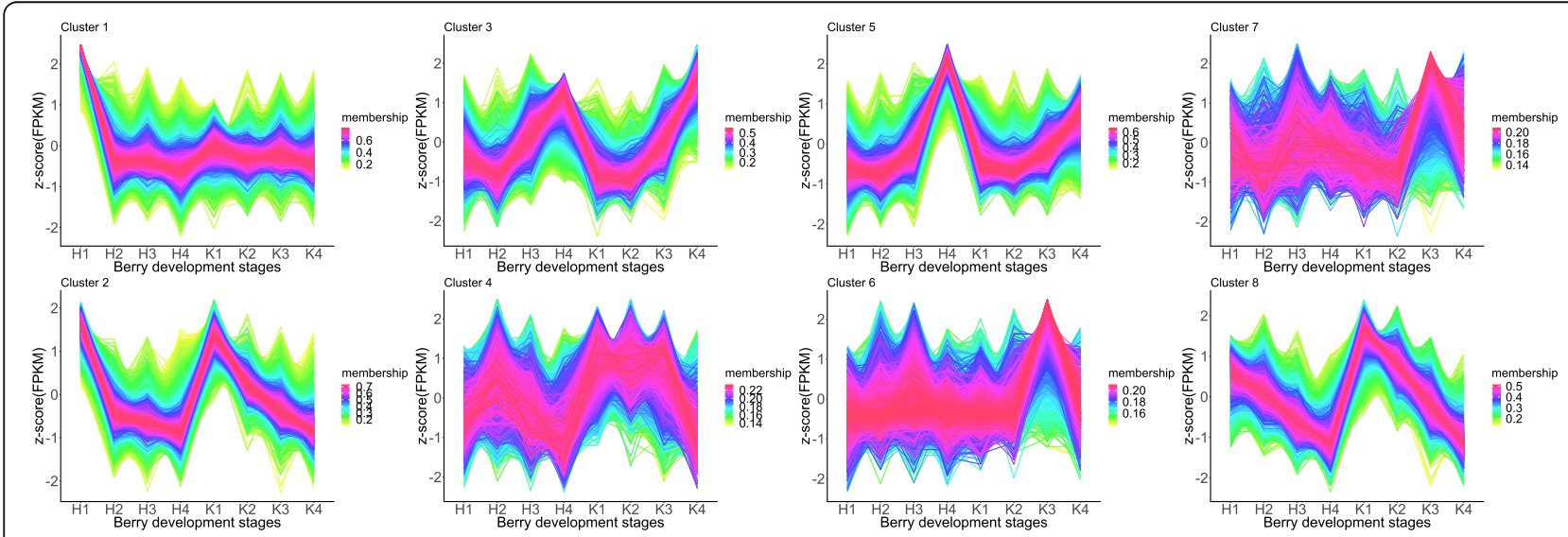

Fig. 2 Cluster analysis of the gene expression patterns in the berry of the control and the treatment of 'Kyoho' across berry developmental stages. Clustering was performed based on TCseq analysis and the number of genes included in each of the clusters is indicated on the top of the figure. The Y-axis represents the FPKM values using 2 as the log base of a gene at different developmental stages. The X-axis represents the berry development. $H$ and $\mathrm{K}$ represent the treatment with $300 \mathrm{mmol} / \mathrm{L} \mathrm{H}_{2} \mathrm{O}_{2}$ and the control, respectively 


\section{a}

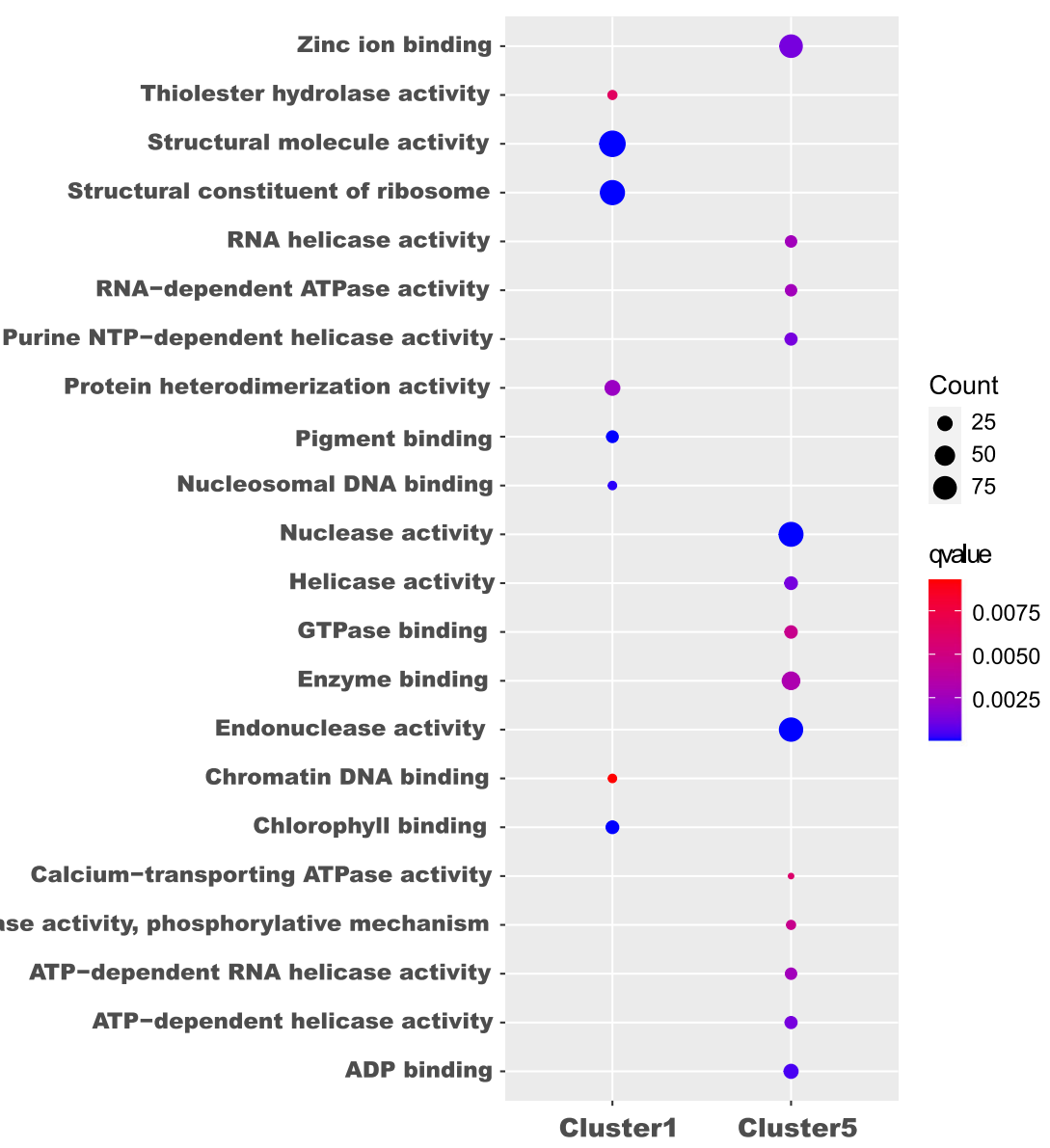

b

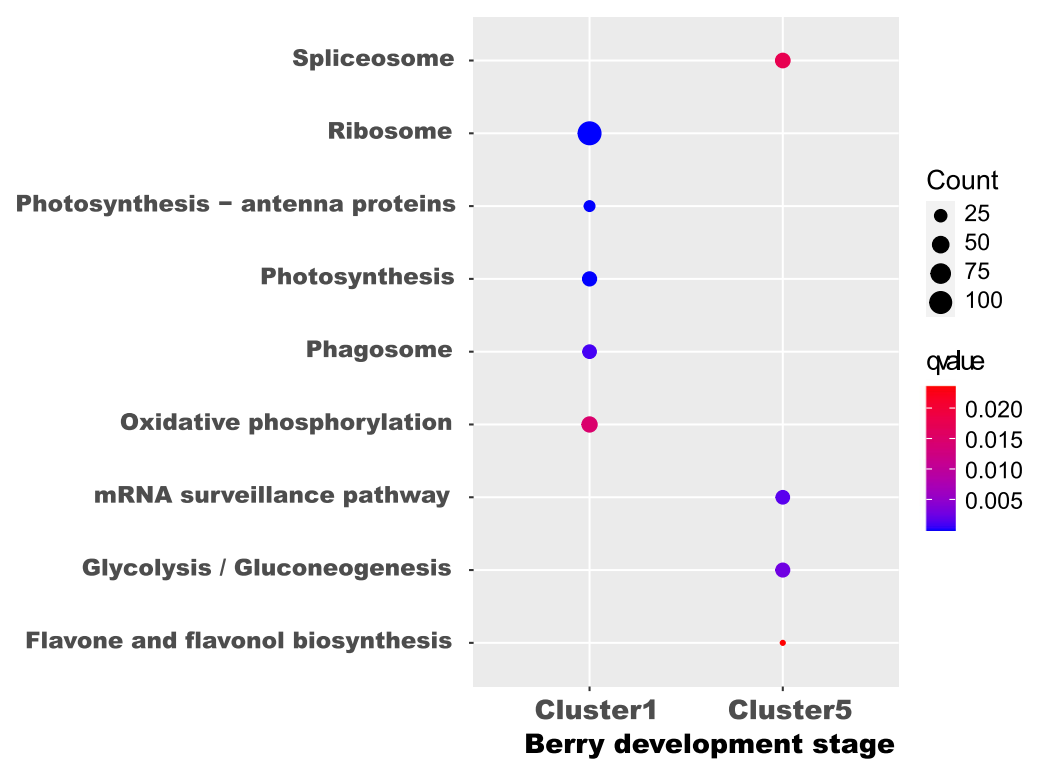

Fig. 3 Scattergram of both GO enrichment analysis and KEGG pathways analysis of cluster 1 and cluster 5 which were different between the control and the treatment from Fig. 2 based on TCseq. The X-axis indicates the berry development stages; the Y-axis indicates the GO terms or KEGG pathway. a GO enrichment analysis of TCseq; b KEGG enrichment analysis of TCseq; Coloring indicates q-value with higher in red and lower in blue. And the lower q-value indicates the more significantly enriched. Point size indicates genes number 
Table 1 List of differentially expressed genes for the treatment over the control after $\mathrm{H}_{2} \mathrm{O}_{2}$ treatment

\begin{tabular}{|c|c|c|c|c|c|}
\hline Stage & Gene ID & Log2FoldChange & padj & Up/Down & Uniprot:Description \\
\hline \multirow[t]{10}{*}{$\mathrm{H} 1-\mathrm{K} 1$} & VIT_19s0090g01050 & 4.580139553 & 0.001810767 & up & Endoglucanase 11 \\
\hline & VIT_01s0137g00240 & 3.347436354 & 0.049115888 & up & Probable pectate lyase 5 \\
\hline & VIT_01s0127g00520 & -1.333128782 & 0.019028882 & down & Probable nucleoredoxin 1 \\
\hline & VIT_05s0020g04840 & -1.42318995 & 0.019028882 & down & GDSL esterase/lipase 7 \\
\hline & VIT_00s0415g00040 & -1.691361575 & 0.03689468 & down & Glycine-rich domain-containing protein 1 \\
\hline & VIT_16s0022g00510 & -1.891347211 & 0.022140035 & down & 23.6 kDa heat shock protein, mitochondrial \\
\hline & VIT_17s0000g03380 & -2.95452543 & 0.02214004 & down & Protein SAR DEFICIENT 1 \\
\hline & VIT_19s0015g00210 & -3.642741092 & 1.13E-06 & down & Zinc transporter 2 \\
\hline & VIT_11s0016g00540 & -3.777944529 & $6.65 \mathrm{E}-06$ & down & Respiratory burst oxidase homolog protein $\mathrm{E}$ \\
\hline & VIT_16s0100g00090 & -7.717325156 & 0.00881588 & down & Peroxidase 66 \\
\hline \multirow[t]{12}{*}{$\mathrm{H} 2-\mathrm{K} 2$} & VIT_05s0029g01540 & 2.301497625 & $2.57 \mathrm{E}-08$ & up & Protein ACCELERATED CELL DEATH 6 \\
\hline & VIT_11s0016g03220 & 2.242129946 & 0.0062515 & up & Probable RNA-dependent RNA polymerase 5 \\
\hline & VIT_12s0028g03120 & 2.120136837 & 0.0069495 & up & Protein E6 \\
\hline & VIT_12s0034g00130 & 2.05843658 & 0.0001454 & up & UDP-glucose flavonoid 3-O-glucosyltransferase 6 \\
\hline & VIT_17s0000g00430 & 1.720472715 & 0.00265815 & up & Transcription factor bHLH137 \\
\hline & VIT_03s0063g02380 & 1.634636111 & $2.69 \mathrm{E}-11$ & up & Organ-specific protein S2 \\
\hline & VIT_05s0077g00030 & 1.610540187 & 0.005766187 & up & Ammonium transporter 1 member 1 \\
\hline & VIT_18s0001g15640 & 1.420949969 & 0.017401315 & up & Pathogen-related protein \\
\hline & VIT_19s0015g00730 & 1.17834606 & $5.58 \mathrm{E}-05$ & up & Cellulose synthase-like protein E6 \\
\hline & VIT_02s0033g01120 & 1.08276489 & $6.76 \mathrm{E}-14$ & up & Probable methyltransferase PMT20 \\
\hline & VIT_05s0062g00250 & -2.248382917 & 2.69E-11 & down & Xyloglucan endotransglucosylase/hydrolase 2 \\
\hline & VIT_18s0089g01270 & -1.677685736 & $1.84 \mathrm{E}-07$ & down & 22.0 kDa class IV heat shock protein \\
\hline \multirow[t]{10}{*}{$\mathrm{H} 3-\mathrm{K} 3$} & VIT_19s0135g00030 & 2.807368996 & 0.027112354 & up & Caffeic acid 3-O-methyltransferase \\
\hline & VIT_18s0164g00100 & 2.740316141 & 0.027112354 & up & Laccase-14 \\
\hline & VIT_14s0006g00250 & 1.461809302 & 0.023518312 & up & Cysteine-rich repeat secretory protein 60 \\
\hline & VIT_11s0016g05330 & 1.345232867 & 0.002817032 & up & SPX domain-containing protein 1 \\
\hline & VIT_13s0067g00990 & 1.032137018 & 0.01657462 & up & Protein SMAX1-LIKE 7 \\
\hline & VIT_11s0016g03010 & -1.21314274 & 0.003481905 & down & Probable glutamate carboxypeptidase 2 \\
\hline & VIT_09s0002g00550 & -1.544214265 & 0.000897028 & down & GDSL esterase/lipase 1 \\
\hline & VIT_01s0010g02290 & -1.614256666 & 0.00078407 & down & $25.3 \mathrm{kDa}$ heat shock protein, chloroplastic \\
\hline & VIT_06s0004g01180 & -1.753589771 & 0.018816772 & down & Peroxidase 15 \\
\hline & VIT_02s0012g01160 & -2.026019129 & 0.018816772 & down & Protein NRT1/ PTR FAMILY 7.3 \\
\hline \multirow[t]{12}{*}{$\mathrm{H} 4-\mathrm{K} 4$} & VIT_04s0079g00690 & 8.803363773 & $2.24 \mathrm{E}-25$ & up & Glutathione S-transferase F12 \\
\hline & VIT_18s0164g00100 & 3.248615391 & $1.11 \mathrm{E}-05$ & up & Laccase-14 \\
\hline & VIT_01s0011g06290 & 1.43663321 & $4.54 \mathrm{E}-13$ & up & Purple acid phosphatase 3 \\
\hline & VIT_19s0015g00210 & 1.332996886 & 0.028360846 & up & Zinc transporter 2 \\
\hline & VIT_09s0002g00550 & -1.796281864 & $8.20 \mathrm{E}-07$ & down & GDSL esterase/lipase 1 \\
\hline & VIT_18s0089g01270 & -1.829201669 & 0.022374842 & down & 22.0 kDa class IV heat shock protein \\
\hline & VIT_16s0022g00510 & -2.41607704 & $2.34 \mathrm{E}-05$ & down & 23.6 kDa heat shock protein, mitochondrial \\
\hline & VIT_10s0003g02890 & -3.111297081 & $5.87 \mathrm{E}-62$ & down & Chlorophyll a-b binding protein 40 , chloroplastic \\
\hline & VIT_02s0154g00480 & -3.601988523 & $4.54 \mathrm{E}-13$ & down & Small heat shock protein, chloroplastic \\
\hline & VIT_08s0058g00210 & -5.111929687 & 0.016649888 & down & 17.3 kDa class I heat shock protein \\
\hline & VIT_17s0000g03940 & -5.756448165 & 0.000924922 & down & Cytochrome P450 CYP736A12 \\
\hline & VIT_07s0031g01710 & -6.950745362 & 0.000216632 & down & Probable WRKY transcription factor 51 \\
\hline
\end{tabular}




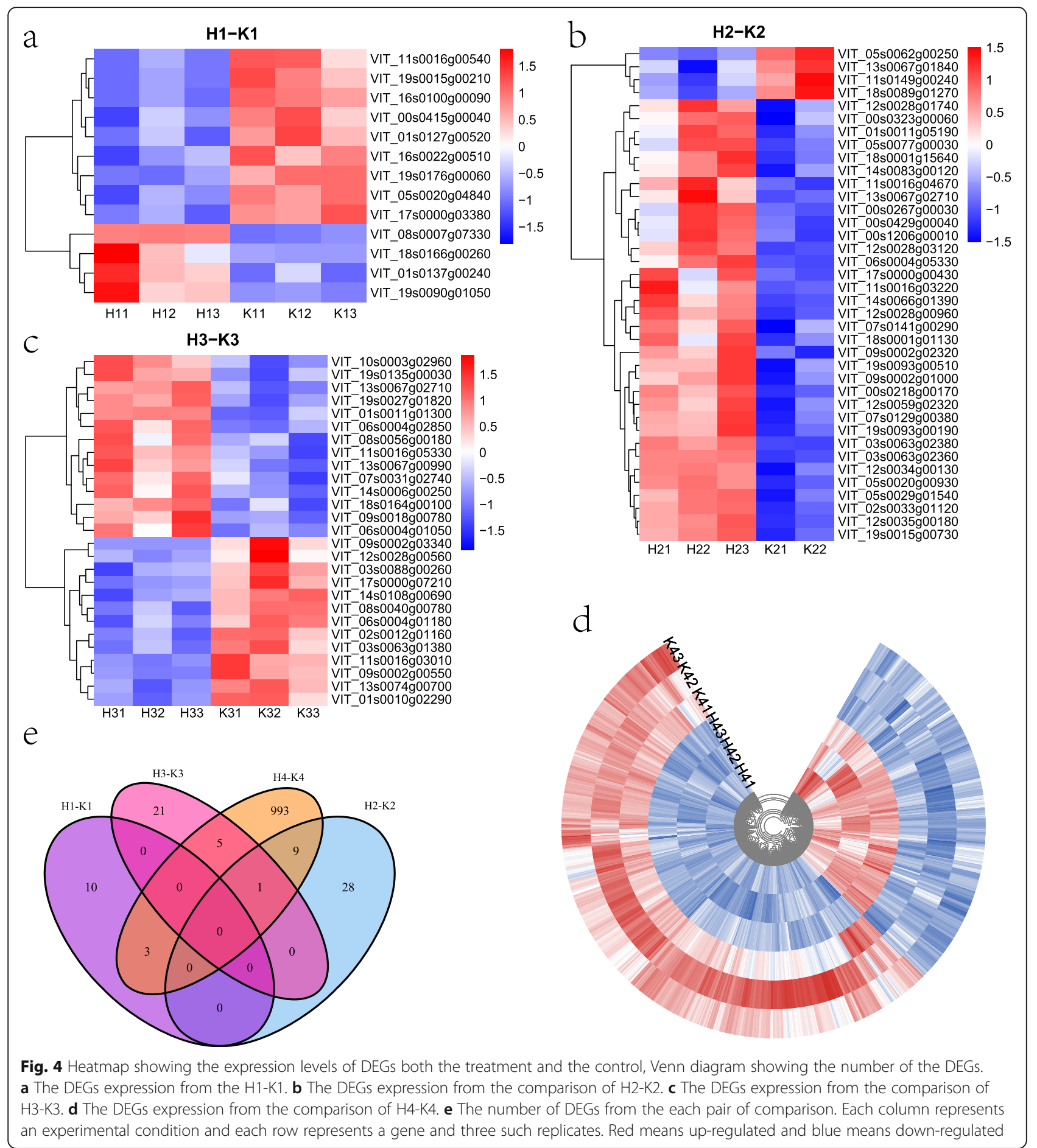

activity (Fig. 5a). The GO enrichment analysis produced no results for the $\mathrm{H} 2-\mathrm{K} 2$ and the $\mathrm{H} 3-\mathrm{K} 3$ comparisons. The KEGG pathway analysis identified eight top pathways, which included, for example, photosynthesisantenna proteins, protein processing in endoplasmic reticulum, and photosynthesis (Fig. 5b). The KEGG enrichment analysis produced no results for the H1-K1 and the H2-K2 comparisons. Notably, pigment binding, chlorophyll binding, and photosynthesis were significantly enriched in the H4-K4 comparison, which are results consistent with those in Fig. 3. The results suggested that the $\mathrm{H}_{2} \mathrm{O}_{2}$ treatment affected the expression of genes associated with photosynthesis and pigment binding. 


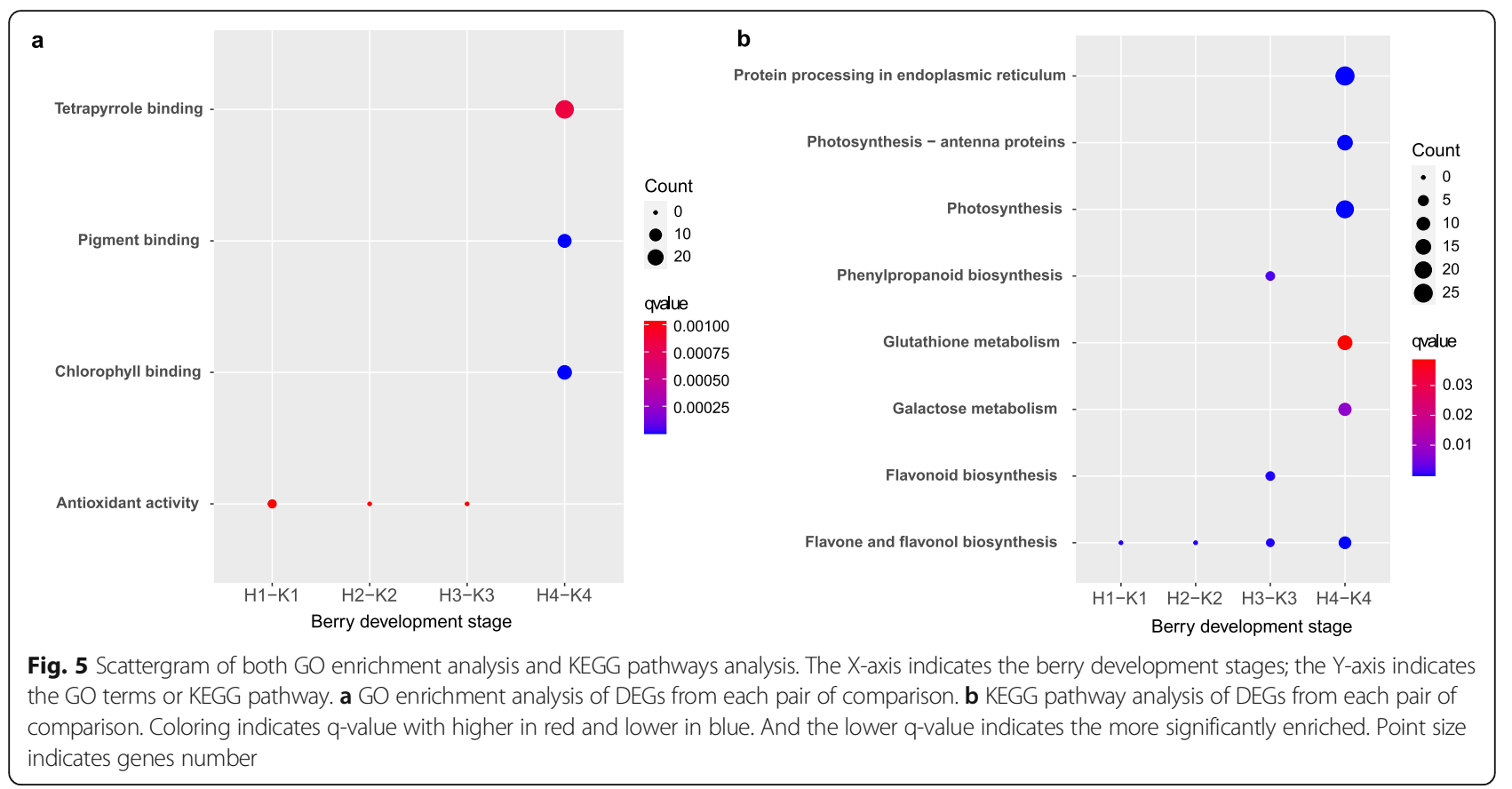

\section{Weighted gene co-expression network analysis}

In this study, weighted gene co-expression network analysis (WGCNA) was conducted on the transcriptomic data sets from Kyoho berries in the $\mathrm{H}_{2} \mathrm{O}_{2}$ treatment. The analysis was conducted using the WGCNA package in R. The modules of highly correlated genes were identified based on the fragments per kilobase per million mapped reads (FPKM) value. Figure 6a shows the heat map of the gene co-expression network. In the figure, the left and top measurements are the results of the gene system cluster tree and the gene network/module analyses, respectively. However, in the heat map at the bottom right, the regions represent the dissimilarity between genes, and the smaller the value is, the darker the color. Generally, with the same genes between modules, the color was darker; whereas the color between

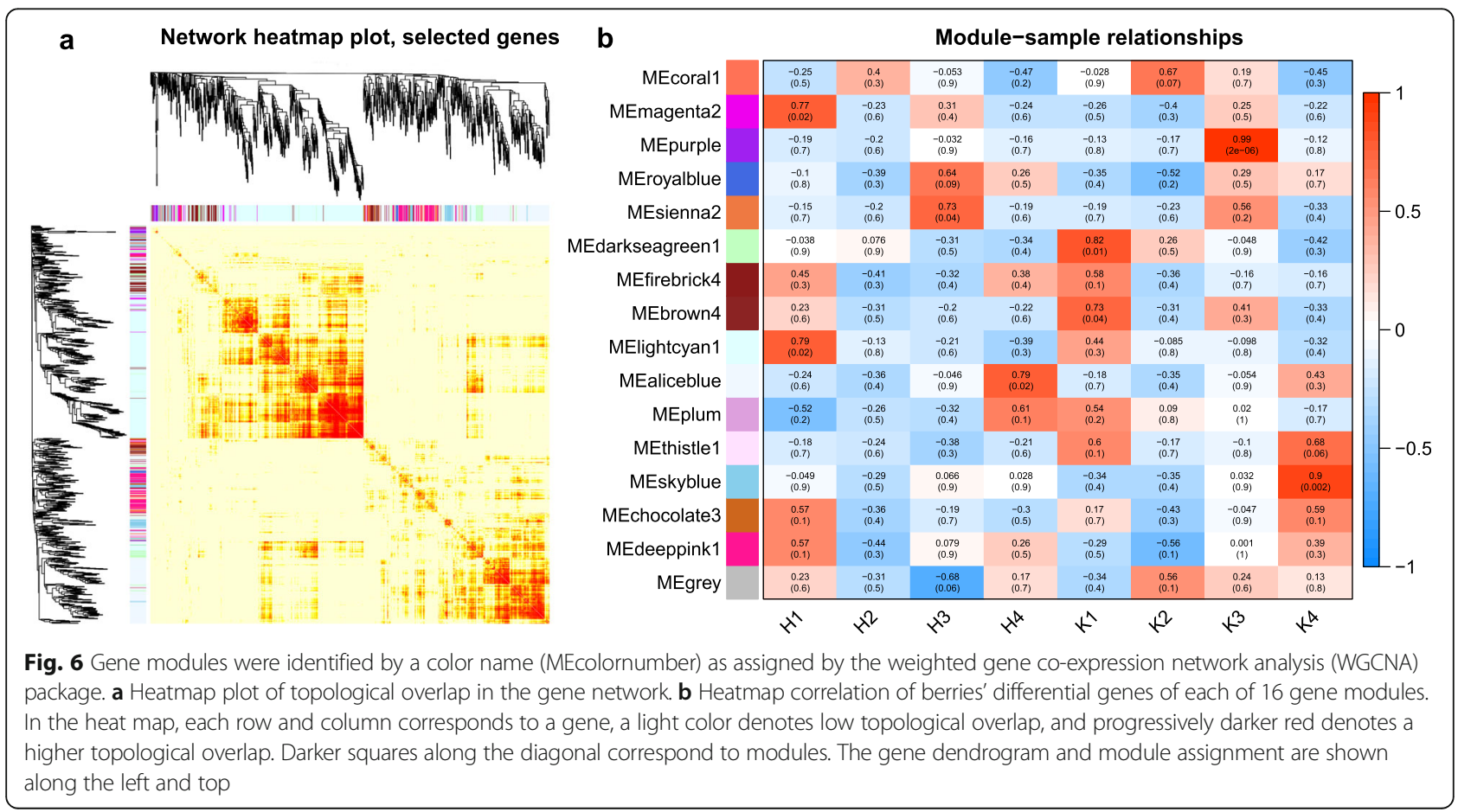


modules was lighter. The co-expression modules were constructed via Pearson's correlation coefficient for gene expression across all samples, and 16 modules were constructed (Fig. 6b). Each cell in Fig. 6b is colored based on the statistical significance and is labeled with two numbers, with the upper number the correlation coefficient and the lower number the $P$-value. Based on the criteria of $P \leq 0.05$ and a Pearson's correlation coefficient greater than 0.7, as shown in Fig. 6b, the modules MEmagenta2, MEsienna2, MEaliceblue, MEdarkseagreen1, MEpurple, and MEskyblue were selected at the H1, H3, H4, K1, K3, and K4 stages, respectively.

To further understand the functions of genes in the modules, GO and KEGG enrichment analyses of each module were conducted to identify its involvement in particular biological processes and metabolic pathways (Supplemental Fig. S4). The top 25 GO terms from the GO enrichment analysis are shown in Supplemental Fig. S4a. Among the GO terms, 21 were in the H1 stage and included, for example, structural constituent of ribosome, structural molecule activity, and microtubule motor activity. Zinc ion binding and nuclease activity were enriched in stage H4; and structural constituent of nuclear pore and glutathione transferase activity were enriched in stages $\mathrm{K} 1$ and $\mathrm{K} 3$, respectively. The GO enrichment analysis produced no results in stages $\mathrm{H} 3$ and K4. The results indicated that the $\mathrm{H}_{2} \mathrm{O}_{2}$ treatment might primarily affect the expression of genes in early stages. A total of 14 KEGG pathways were enriched (Supplemental Fig. S4b). Six pathways, which included, for example, ribosome, protein export, proteasome, DNA replication, and biotin metabolism, were enriched in stage H1. The four pathways of mRNA surveillance pathway, glycolysis/gluconeogenesis, fatty acid degradation, and arachidonic acid metabolism were enriched in stage $\mathrm{H} 4$ stage. The other enriched pathways of glutathione metabolism, protein processing in endoplasmic reticulum, chlorophyll metabolism, and one carbon pool by folate were in stages $\mathrm{K} 3$ and K4. The KEGG enrichment analysis produced no results in stages $\mathrm{H} 3$ and $\mathrm{K} 1$. To summarize, the $\mathrm{H}_{2} \mathrm{O}_{2}$ treatment primarily affected the expression of genes in early berry developmental stages (Supplemental Fig. S4).

\section{Reconstruction of gene co-expression network}

Hub genes were identified by sorted $K_{M E}$ values, which indicated the eigengene connectivity in the WGCNA analysis [23]. The co-expression network of individual co-expression modules was visualized using Cytoscape software [24]. In this study, some hub genes were selected from the highest $K_{M E}$ values of each significantly different module. Based on the results of a previous study [22], the focus was on the hub genes GDSL (GDSL esterase/lipase, VIT_05s0077g00870) and XTH30 (xyloglucan endotransglucosylase/hydrolase protein 30 , VIT 02s0012g02220). Figure 7 shows that GDSL and XTH3O included 17 and 11 edges, respectively, and all gene annotations are shown Supplemental Table S3. Supplemental Fig. S2 shows the networks of H1, K1, K3, and $\mathrm{K} 4$, and the annotation of the respective hub genes was as uncharacterized protein; hypothetical zinc ion binding protein, hypothetical protein; udp-glucose flavonoid 3-oglucosyltransferase 6-like, probable glutathione stransferase; $18.2 \mathrm{kDa}$ class I heat shock protein; and 18.6 $\mathrm{kDa}$ class III heat shock protein.

\section{Verification of differentially expressed genes and hub genes by RT-qPCR}

To verify the RNA-sequencing results of DEGs and hub genes, 14 DEGs (XTH15, CAB1, HSP21, ATHSP22, HSP23, PAP, OMT1, GLIP, GSTF12, LAC14, VIT_205s0020g04840, VIT_208s0058g00210, and VIT_217s0000g00430) and one hub gene (XTH30) were selected to perform RT-qPCR (Fig. 8; a

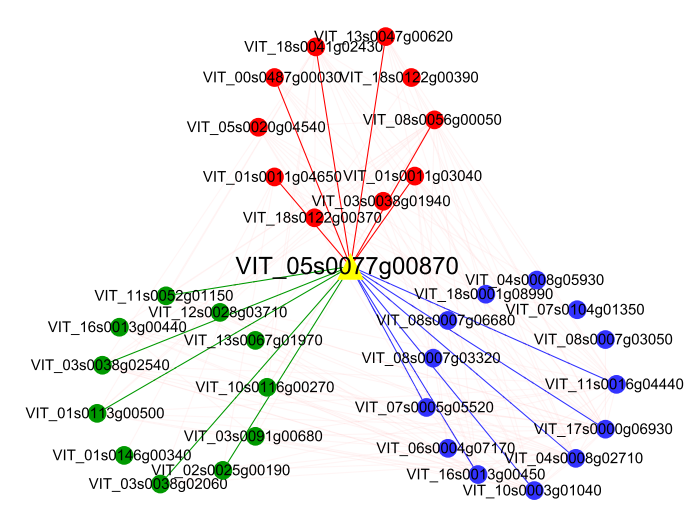

b

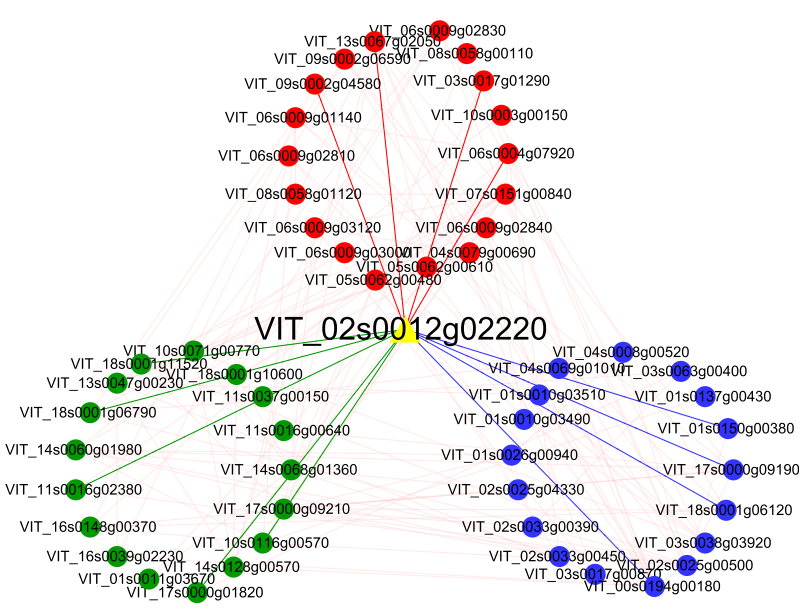

Fig. 7 Cytoscape representation co-expressed genes with edge weight $\geq 0.10$. The important hub gene was noted with yellow. a The hub gene of the $\mathrm{H} 3$ stage. $\mathbf{b}$ The hub gene of the $\mathrm{H} 4$ stage, respectively 

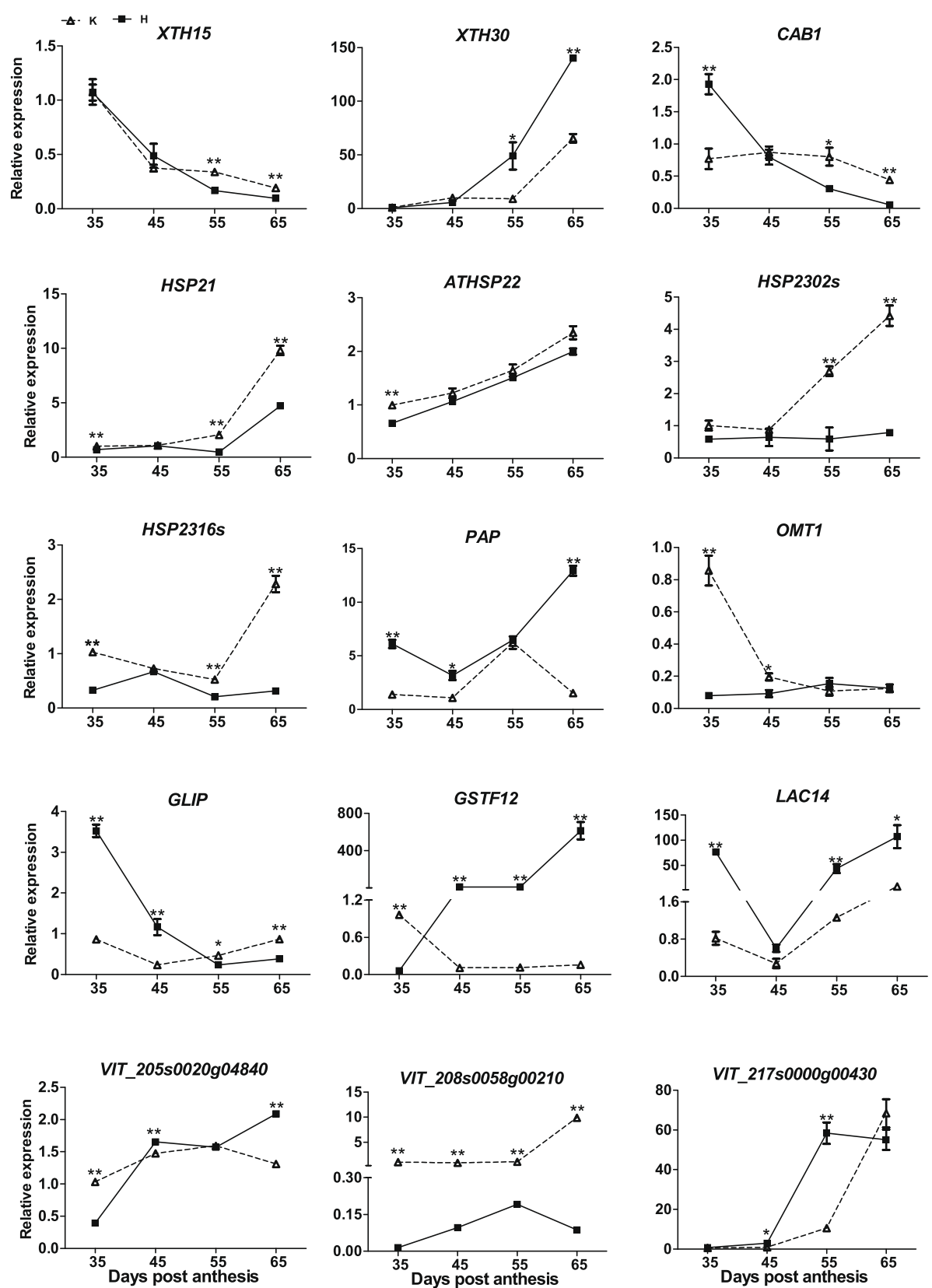

Fig. 8 qRT-PCR expression patterns of both 14 DEGs and one hub genes detected in the RNA-Seq profiles of the control and the treatment. Three biological replicates are used for qRT-PCR validation. Significant differences between means were made using One-way ANOVA followed by Tukey's HSD post hoc test. Error bars represented standard deviations from three independent biological replicates. The asterisk $(*)$ stands for the levels of significant difference $\left({ }^{*} p\right.$ value $\leq 0.05,{ }^{* *} p$ value $\left.\leq 0.01\right)$

Supplemental Table. S5). In the comparison between the control and the treatment, the expression levels of XTH15, CAB1, HSP21, HSP23, and VIT_208s0058g00210 in the treatment were significantly lower than those in the control at 55 days post anthesis (dpa). Compared with the control, the relative expression levels of XTH30, GSTF12, LAC14, and $V I T$ 217s0000g00430 were significantly higher in the treatment at $55 \mathrm{dpa}$. The relative expression profiles of ATHSP22 were similar. The relative expression level of GLIP in the treatment was higher than that in the control at 35 and 45 $\mathrm{dpa}$, whereas the relative expression level of OMT1 in the treatment was lower than that in the control at 35 and 45 dpa. Thus, the results of RNA sequencing and RT-qPCR were largely consistent. Linear regression [(qRT-PCR value $=a($ RNA-seq value $)+b]$ analysis showed that the transcript abundance assayed by real-time PCR and the transcription profile revealed by RNA-seq data were highly correlated $\left(R^{2}=0.7874\right)$ (Supplemental Fig. S3). 


\section{Discussion}

Hydrogen peroxide is a crucial ROS in biological processes that contributes to tolerance against a variety of stresses $[25,26]$ and is also a secondary messenger that regulates the development and growth of plants to some degree [27]. In addition, according to previous results, Kyoho berries with $\mathrm{H}_{2} \mathrm{O}_{2}$ treatment ripened 20 days earlier than the control [10]. Nevertheless, the effect of $\mathrm{H}_{2} \mathrm{O}_{2}$ treatment on changes in the expression of genes of Kyoho is currently not understood. RNA sequencing can measure the expression level of each gene in a sample and also helps to reveal the expressional differences among different samples [28, 29]. Hence, RNA sequencing was used to identify the changes in gene expression after $\mathrm{H}_{2} \mathrm{O}_{2}$ treatment. We may miss these genes. That need the extensive sampling points. Furthermore, if this is true, the changes of assumed genes will affect a series of changes of other genes, its effect will not disappear, otherwise, it could not promote the early ripening of the grape, the present study primarily caught these. And we indeed collected the samples shortly after the treatment for the first sampling point.

A total of 1089 DEGs were identified in the RNAsequencing data (Fig. 4). To determine the common DEGs in the comparison of the same stages, Venn diagrams were constructed (Fig. 4e). However, no DEGs were shared in the comparisons of the same stages. This result may be because few DEGs were identified in the early berry developmental stages. Based on the reasons given above, TCseq (Fig. 2) and WGCNA (Fig. 6) analyses were performed. The TCseq showed that most of the genes had similar expression profiles (Fig. 2), i.e., the $\mathrm{H}_{2} \mathrm{O}_{2}$ treatment did not cause dramatic changes in gene expression, although some key pathways might have been affected. GO enrichment analysis revealed that the pathway of chlorophyll binding was enriched, as shown in Fig. 3a and Fig. 5a; and the KEGG enrichment analysis revealed that photosynthesis-antenna proteins and photosynthesis pathways were enriched, as shown in Fig. $3 \mathrm{~b}$ and Fig. 5b.

Chlorophyll is essential in photosynthesis [30], which has an important role in the physiological processes of plant growth and development [31]. Many studies demonstrate that oxidative stress can interfere with photosynthesis [32, 33], which causes an imbalance in the electron transport chain in chloroplasts, thereby accelerating the production of ROS [34] and causing oxidative damage [35], accelerating plant senescence [36]. In addition, Yu et al. [37] found that abiotic stress can destroy the photosynthetic apparatus, which results in changes in the expression levels of proteins associated with photosynthesis, reducing photosynthesis and causing early senescence. In this study, the pathway of chlorophyll binding was enriched in cluster 1 and in the comparison of stages H4-K4 (Fig. 3a and Fig. 5a), and the pathways of photosynthesis and photosynthesisantenna proteins were enriched in cluster 1 (Fig. $3 \mathrm{~b}$ ) and in the comparison of stages $\mathrm{H} 4$ and K4 (Fig. 5b).

The role of photosynthesis in fruit development and ripening has been much discussed [38]. Therefore, the search for mechanisms that underlie the variability in photosynthesis during fruit ripening is an important direction in the research to better understand the process of fruit ripening [39]. At present, most of the works that examine photosynthesis in fruit during ripening involve tomato. According to Cocaliadis et al. [40], with the induction of higher photosynthesis during the green stages, tomato fruit ripening can be delayed. In addition, Piechulla et al. [41] found that photosynthesis decreases during tomato fruit ripening. Wang et al. [42] used combined metabolomic and transcriptomic analyses and also reported that photosynthesis is important in tomato fruit ripening. These studies show that although the peel of mature green fruits is photosynthetically active, there is a gradual decrease in the intensity of photosynthesis during ripening [43]. In this study, both GO enrichment and KEGG pathway analyses revealed the importance of the photosynthesis pathway (Fig. 3), and the genes associated with photosynthesis were screened for further analysis via DEG, Tcseq, and WGCNA analyses.

The chlorophyll a/b-binding proteins (CABs) are the apoproteins of the light-harvesting complex of photosystem II (PSII) in higher plants [44]. CABs are normally part of the antenna complex [45]. According to Ma and Yang et al. [46], multiple genes encode CABs in higher plants. In a previous report, an increase in the expression of the $C A B$ gene caused the accumulation of chlorophyll and stability in the chloroplast thylakoid membranes in green tomato fruit [47]. Silva et al. [48] found that the expression of $C A B s$ is affected by abiotic stress, which indicated the $C A B$ gene plays an important role in abiotic resistance. Peralta et al. [49] reported that with an increase in the expression levels of $C A B 1$, there is a lack of yellowing in rosette leaves, and therefore, the increase in the expression level delays leaf senescence. In addition, melatonin can delay senescence in kiwifruit leaves by maintaining the chlorophyll content [50]. When the expression of $C A B$ is down-regulated, the kiwifruit leaves are in senescence. However, melatonin treatment increases the expression of the $C A B$ gene and delays the senescence of kiwifruit leaves [50]. In this study, CAB1 (VIT_10s0003g02890, chlorophyll a-b binding protein 40) was significantly down-regulated after $\mathrm{H}_{2} \mathrm{O}_{2}$ treatment (Table 1), and the RT-qPCR results showed that the expression of the $C A B 1$ gene was significantly lower in the treatment than in the control at 55 dpa (Fig. 8). Notably, $\mathrm{H}_{2} \mathrm{O}_{2}$ treatment causes veraison of Kyoho at $55 \mathrm{dpa}$ [10]. The above results indicated that 


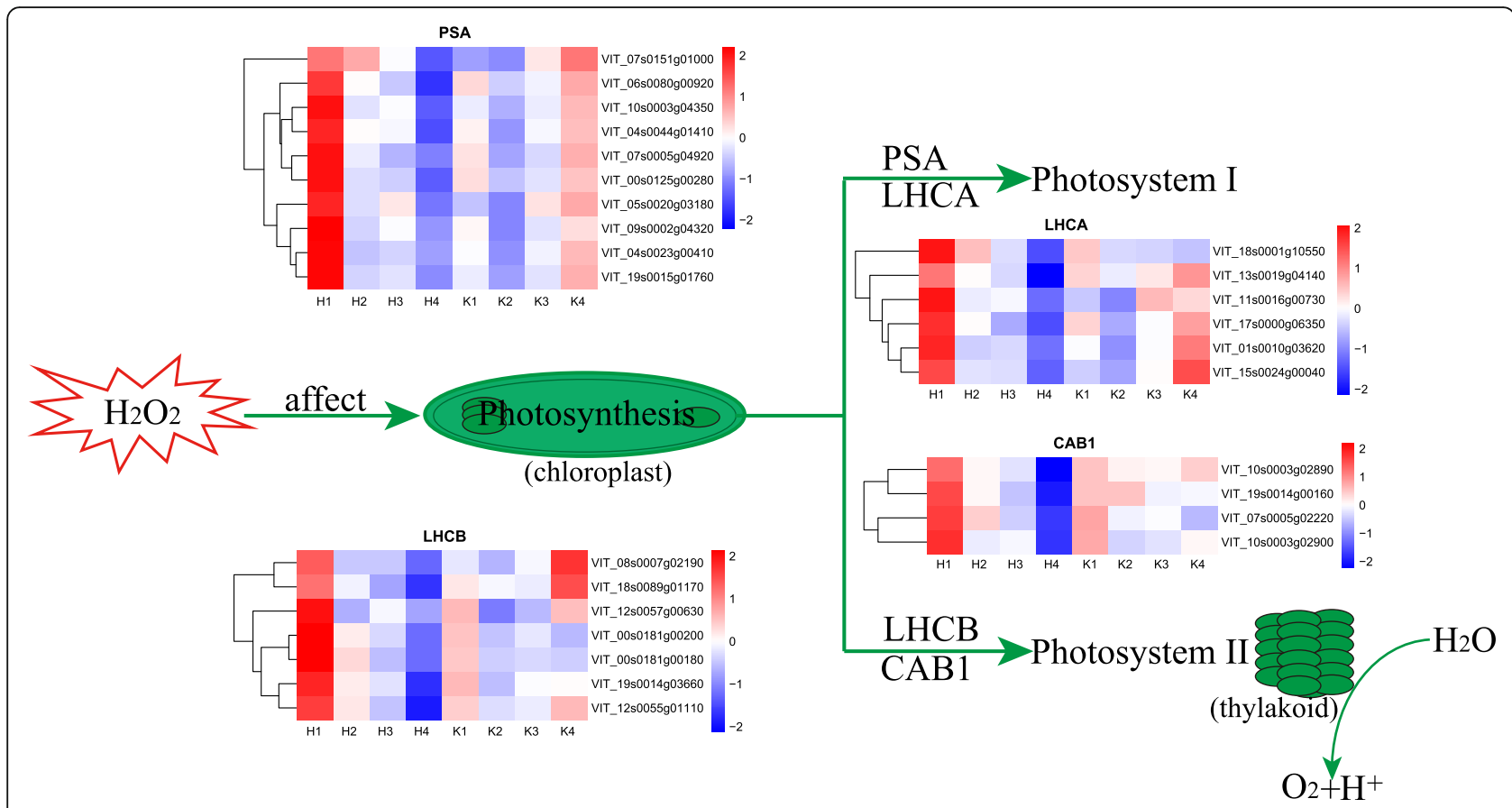

Fig. 9 Heatmap showing the expression patterns of genes involved in the photosynthesis pathway both in the treatment and the control

the $\mathrm{H}_{2} \mathrm{O}_{2}$ treatment inhibited the expression of $C A B 1$ and thereby promoted early berry ripening. These results are consistent with those of Liang et al. [50]. In addition, other genes (PSA, LHCB, and $L H C A$ ) associated with photosynthesis were affected by the exogenous $\mathrm{H}_{2} \mathrm{O}_{2}$ treatment (Fig. 9), and these genes might also play a crucial role in early berry ripening.

Heat shock proteins (HSPs) are molecular chaperones that reduce the damage due to multiple stresses [51]. Driedonks et al. [52] found that the HSPs can also protect cells against abiotic stresses by interacting with ROS-scavenging genes. On the basis of protein size, amino acid sequence homology, and function, HSPs are classified into five subfamilies, including small HSPs (sHSPs) [53]. Hilton et al. [54] reported that HSPs represent the first line of defense in a cell to prevent protein misfolding. In addition, sHSPs are important defenseinduced factors and play key roles not only in the response to oxidative stress but also in the response to drought, salt, cold, and heat stress $[55,56]$. The overexpression of sHSPs protects photosystem II from oxidative stress in tomato and tobacco [57, 58]. Ji et al. [59] showed that HSP genes promoted the ripening of grape berries by using a gene family analysis, a structured phylogenetic tree, a subcellular localization study, and further functional analysis. In the RNA sequencing of tomato fruit, four differentially expressed HSP genes were identified, which were considered to play a key role in fruit ripening [60]. The NJJS4 gene is a type of HSP20coding gene, which participates in regulating strawberry fruit ripening [61]. In addition, Arce et al. [62] report that the sHSP gene family in tomato is related to fruit ripening, as indicated by the sequence-conserved promoter architecture. Moreover, an sHSP influences pectin depolymerization in tomato fruit ripening [63]. In a proteome-wide study, eight HSP genes were associated with tomato fruit development and ripening [64], demonstrating that HSP genes indeed participate in tomato fruit ripening [65]. Stress is a well-known stimulus that triggers the induction of sHSPs [62]. In particular, sHSPs are also induced during tomato ripening [66], suggesting that the stress induced affected the HSP genes, thereby causing tomato fruit ripening. In this study, the exogenous $\mathrm{H}_{2} \mathrm{O}_{2}$ treatment was equivalent to exogenous stress in the Kyoho grape berry and therefore affected the expression of HSP genes, which resulted in the berry ripening. In a previous study, riboflavin treatment affected the expression of HSP genes [22]. On the basis of that study, in this study, five DEGs were selected that were associated with HSPs: ATHSP22 (VIT_18s0089g01270), VIT_208s0058g00210 (VIT_08s0058g00210), HSP23 (VIT_16s0022g00510, VIT_02s0154g00480), and HSP21 (VIT_01s0010g02290). RT-qPCR was used to verify the expression of those genes (Fig. 8).

The expression of most HSP genes in the treatment group was significantly lower than that in the control group at $55 \mathrm{dpa}$ (Fig. 8). However, with $\mathrm{H}_{2} \mathrm{O}_{2}$ treatment, Kyoho berries ripen 20 days earlier than those in in the control [10]. The results suggested that $\mathrm{H}_{2} \mathrm{O}_{2}$ treatment down-regulated the expression of HSP genes, which may 
increase the level of oxidative stress. Oxidative stress can be best assessed by the extent of lipid peroxidation catalyzed by lipoxygenase [67]. Catalase is one of the primary enzymatic defenses against oxidative stress induced by senescence [68], and when superoxide dismutase (SOD) decreases during fruit senescence, the $\mathrm{O}_{2}-$ concentration increases, thereby causing oxidative stress [69]. Lipoxygenase, catalase, and SOD are associated with ROS metabolism [70]. Oxidative stress can cause the accumulation of ROS, and by causing cellular membrane damage; the excess ROS participate in the process of fruit ripening [71, 72]. According to Chin et al. [73], control of oxidative stress in mango fruits can extend the shelf life in the postharvest stage. Thus, these results demonstrate that oxidative stress regulates fruit ripening by regulating ROS metabolism. By contrast, the overexpression of HSP genes can alleviate damage caused by abiotic stresses in Arabidopsis and rice, thereby delaying senescence [74, 75]. Previous results also indicate that exogenous ROS treatment can promote the early ripening of berries by affecting the expression HSP genes [10, 22]. However, the relationship between HSPs genes and berries ripening is unclear at present. i.e. it indeed could not distinguish "cause" and "effect".

The GDSL esterases belong to a family of lipid hydrolysis enzymes in higher plants [76]. These esterases/ lipases have been identified in grape (96 members), western balsam poplar (126), sorghum (130), and moss (57) [77]. The GDSL esterases/lipases have a crucial role in the regulation of plant growth and development, morphogenesis, synthesis of secondary metabolites, and defense response [78]. Fatty acids are the major energy reserve substance stored in the mature seeds of many higher plants and can regulate plant growth and development [79]. In the enrichment analysis, the pathway of fatty acid degradation was identified at stage H4 (Supplemental Fig. S4b). Huang et al. [80] report that the GDSL esterases/lipases can degrade fatty acids in mature Arabidopsis seeds. Acetylation modifies the cell wall and is beneficial to the formation of secondary wall architecture [81]. The GDSL esterases/lipases remove acetyl groups from the xylan backbone [81], and as a result, the enzymes promote the softening of cell walls by deacetylation. The GDSL esterases/lipases also play an important role in plant defense responses [82]. GLIP1 exhibits antimicrobial activity and has positive roles in defense in Arabidopsis [83]. Gao et al. [84] found that the down-regulation of GLIP1 increases rice resistance to pathogens, but with the overexpression of GLIP1, disease resistance decreases significantly in rice. The results suggest that the GLIP1 has an important role in disease resistance and in the response to abiotic stress in rice. In addition, $\mathrm{Ni}$ et al. [85] show that GLIP1 may be associated with grape ripening. Notably, in a previous study,
ROS and pathogenesis-related (PR) genes had key roles during grape berry ripening, in addition to the genes of some cell wall-degrading enzymes [20].

The GLIP1 (VIT_09s0002g00550) and VIT 205 s0020g04840 were the DEGs identified in the present study. The RT-qPCR revealed that the expression level of GLIP1 in the treatment was significantly higher than that in the control at 35 and 45 dpa. However, at $65 \mathrm{dpa}$, the expression level of GLIP1 in the treatment was significantly lower than that in the control (Fig. 8). It is just the assumption based on the published reports about the function of GLIP. GLIP1 was selected due to its differentially expression both in RNAseq and qRT-PCR analysis. We just showed the expression characterization which may be related. Of course, more proof is needed in the future.

Fruit softening is associated with the modification of xyloglucan [86], and xyloglucan plays a crucial role in loosening or stiffening the cell wall by binding to cellulose $[87,88]$. Hemicellulose is a polysaccharide component of the primary cell wall, and the depolymerization of hemicellulose is responsible for fruit ripening [89]. Xyloglucan endotransglycosylase/hydrolases (XTHs) are cell wall enzymes with hydrolase and endotransglycosylase activities [90]. The XTHs can catalyze endolytic cleavage of xyloglucan polymers, thereby promoting fruit softening [86]. The XTH genes also participate in the degradation of cell walls [91] and are involved in fruit softening [92, 93]. Yun et al. [94] confirm that an XTH gene can promote the ripening of banana fruit by the degradation of hemicelluloses. Similarly, an XTH gene can cause the ripening and softening of kiwifruit [95].

In this study, XTH15 (VIT_05s0062g00250) (Fig. 4b) and XTH30 (VIT_02s0012g02220) (Fig. 7b) genes were selected. RNA sequencing showed that XTH15 was significantly down-regulated in the treatment group (Table $1)$. Compared with the control, the expression level of XTH15 was significantly lower in the treatment at 55 dpa. However, the expression level of XTH3O was significantly higher in the treatment than that in the control at 55 dpa (Fig. 8).

Shi et al. [96] found that XTH15 is strongly expressed in young organs of Arabidopsis, suggesting that it play roles in cell expansion, although hydrolytic activity was undetectable. This result suggests that XTH15 has only endotransglycosylase activity. Divol et al. [97] show that $X T H 15$ and XTH3O are in different main groups, according to a gene family analysis. Thus, XTH15 and XTH30 may play different roles in fruit development and ripening. Yan et al. [98] show that the knockout of XTH3O results in a lower level of $\mathrm{H}_{2} \mathrm{O}_{2}$ in the mutant than in the wild type, thereby alleviating oxidative damage in Arabidopsis. The result suggests that XTH3O is associated with ROS. In this study, the expression level of XTH3O was 
significantly higher in the treatment than in the control at $55 \mathrm{dpa}$. Therefore, the $\mathrm{H}_{2} \mathrm{O}_{2}$ treatment promoted the expression of XTH3O, which increased the oxidative damage and caused early ripening of berries. The XTH15 gene may only regulate cell expansion in early berry developmental stages, and therefore, the function of XTH15 needs to be studied further. In addition, the relationship between XTH15 genes and berries ripening is unclear. The present study just demonstrated XTH15 after the $\mathrm{H}_{2} \mathrm{O}_{2}$ treatment. The clarification of cause or effect need more further study to explore it. We will do some transgenic study to test it in the future. To summarize, the $\mathrm{H}_{2} \mathrm{O}_{2}$ treatment interfered with photosystem II, causing the accumulation of ROS and thereby promoting the ripening of fruit. The genes GDSL and $X T H$ promoted cell wall degradation by removing the acetyl group of xylan and catalyzing xyloglucan polymers, respectively, also causing berry ripening (Fig. 10).

\section{Conclusions}

In this study, transcriptome analysis was used to investigate the molecular mechanism by which $\mathrm{H}_{2} \mathrm{O}_{2}$ treatment promotes the early ripening of Kyoho berries. Differentially expressed gene, TCseq, GO, KEGG, and WGCNA analyses were used to screen candidate genes and some key pathways. Some DEGs associated with berry ripening were identified, and included $H S P$, GDSL, $C A B 1$, and $X T H$ genes. The major genes were related to oxidative stress (HSP genes: including VIT_18s0089g01270, VIT_16s0022g00510, VIT_08s0058g
00210, VIT_02s0154g00480, and VIT_01s0010g02290; functional annotation: heat shock protein), cell wall deacetylation (GDSL genes: including VIT_09s0002g00550 and VIT_05s0020g04840; functional annotation: GDSL esterase/ lipase), cell wall degradation (XTH genes: including VIT 05s0062g00250 and VIT_02s0012g02220; functional annotation: xyloglucan endotransglucosylase/hydrolase), and photosynthesis (CAB1 gene: VIT_10s0003g02890; functional annotation: chlorophyll a-b binding protein). In addition, the TCseq, KEGG, and WGCNA analyses revealed that photosynthesis was a key pathway during berry ripening. In summary, RNA-sequencing analysis indicated that $\mathrm{H}_{2} \mathrm{O}_{2}$ treatment promoted Kyoho berry early ripening by affecting the expression levels of these genes and pathways.

\section{Methods}

Plant material

Five-year-old Kyoho vines were obtained from Yanshi County, Luoyang, China $\left(34.41^{\circ} \mathrm{N}, 112.46^{\circ} \mathrm{E}\right)$, and were cultivated from cuttings at the experimental farm of Henan University of Science and Technology. The berries were identified and stored in the laboratory. Field management was conducted according to local agricultural practices. The concentration of $30 \% \mathrm{H}_{2} \mathrm{O}_{2}$ was 300 $\mathrm{mmol} / \mathrm{L}$. Distilled water was used for dilution, and the surfactant was Silwet-77 (Solarbio, Beijing, China) added at $300 \mu \mathrm{L} / \mathrm{L}$. Twenty milliliters of the solution was sprayed evenly on the young berries of each cluster twice, and the treatment method followed that described

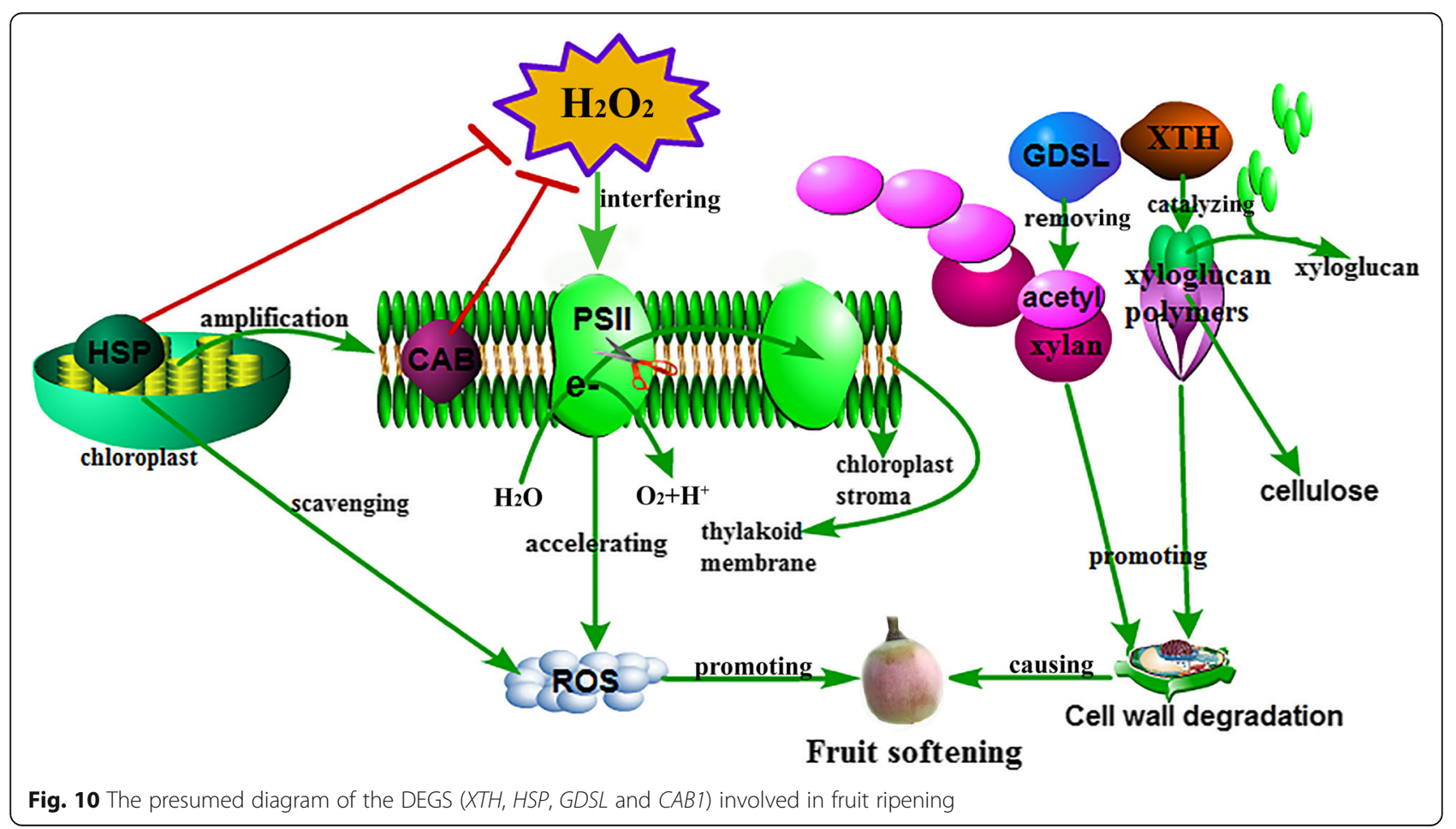


Table 2 Sampling time points of Kyoho bunches treated with or without hydrogen peroxide in 2017

\begin{tabular}{lllll}
\hline Days post anthesis & & & & \\
\hline Treatment sampling time & $35(\mathrm{H} 1)$ & $45(\mathrm{H} 2)$ & $55(\mathrm{H} 3)$ & $65(\mathrm{H} 4)$ \\
Control sampling time & $35(\mathrm{C} 1)$ & $45(\mathrm{C} 2)$ & $55(\mathrm{C} 3)$ & $65(\mathrm{C} 4)$ \\
\hline
\end{tabular}

Note: The sprayings were conducted on June 13 (35 dpa) and June 23 (45 dpa), respectively

in a previous study [10]. The first and second sprayings were applied at 25 and 35 days post anthesis (dpa), respectively, in 2017. The control received $20 \mathrm{~mL}$ of distilled water with $300 \mu \mathrm{L} / \mathrm{L}$ of Silwet-77. Each treatment was replicated three times. Thirty bunches were sampled from five vines, with the 30 bunches as one replication. The information on the sampling time points is provided in Table 2.

\section{Total RNA extraction, library construction, and RNA sequencing}

Total RNA was isolated from Kyoho grape berries in the treatment and control groups using an RNAprep Pure Plant Kit (Polysaccharides \& Polyphenolics rich, DP441; Tiangen, Beijing, China) according to the manufacturer's instructions. The RNA was extracted from whole berries without the seeds. The berries, $0.5 \mathrm{~g}$, were ground, and $0.1 \mathrm{~g}$ of tissue was used for each extraction. The experimental method was according to the manufacturer's instructions. RNA integrity was evaluated with an RNA Nano 6000 Assay Kit using a Bioanalyzer 2100 system (Agilent Technologies, CA, USA). Three biological replicates were analyzed.

The sequencing libraries were constructed using a NEBNext $^{\circ}$ Ultra $^{\text {TM }}$ RNA Library Prep Kit for Illumina ${ }^{\circ}$ (NEB, USA) according to the manufacturer's instructions. The mRNA was separated and purified from total RNA using magnetic beads oligo (dT). A total of $3 \mu \mathrm{g}$ of mRNA per sample was used as material for library construction. The purified mRNA was fragmented using fragmentation buffer. Then, the first-strand cDNA and the second strand were biosynthesized and purified with a QIAQuick PCR kit (Beijing Zhijie Fangyuan Technology Co. Ltd., China), and EB buffer was added for elution. After elution and purification, the double-stranded cDNA was repaired at the ends and the base ' $\mathrm{A}$ ' and the sequencing joint were added. The target fragments were recovered with agarose gel electrophoresis. The PCR products were purified with an AMPure XP system (Beckman Coulter, Indianapolis, IN, USA), and the library quality was assessed with an Agilent 2100 Bioanalyzer. Three biological replicates were sequenced for each sample on an Illumina $\mathrm{HiSeq}^{\mathrm{TM}} 2500$ platform at the Anoroad Genome Technologies Co., Ltd. (Beijing, China).
Sequence data filtering, de novo assembly, and annotation

After trimming the adaptor sequences and removing poly$\mathrm{N}$ reads and low-quality sequences with more than $50 \%$ bases and $\mathrm{Q}_{\text {phred }} \leq 19$ from the raw data of RNA sequencing, the clear reads were assembled by HISAT2 with default parameters. Bowtie (1.0.1 version) was used to build the index of the reference genome, and HISAT2 (2.1.0 version; Kim et al. [99]) was used to map the clean reads to the reference genome (ftp://ftp.ensemblgenomes.org/ pub/plants/release-38/fasta/vitis_vinifera). To functionally annotate genes, all assembled transcripts were mapped to sequences available in public databases, including the non-redundant protein (NR) (http://www.ncbi.nlm.nih. gov/) and Swiss-Prot [100], Protein family (Pfam) [101], Gene Ontology (GO) [102], Clusters of Orthologous Groups (COG) [103], euKaryotic Orthologous Groups (KOG) [104] and Kyoto Encyclopedia of Genes and Genomes (KEGG) [105] databases.

\section{Cluster and differentially expressed gene analyses}

Following alignments, raw counts of total genes were normalized to FPKM. According to the gene expression level, two was used as the log base. The value of mean expression was calculated at different berry developmental stages for each expressed gene. The TCseq clustering method was used to characterize the expression patterns of total genes [106].

The gene expression levels were quantified with FPKM values. HTseq (0.6.0 version) was used to count the number of clean reads mapped to each predicted gene. The DESeq2 [107] R package (1.6.3 version, TNLIST, Beijing, China) was used to identify differentially expressed genes based on the read count of each gene at different developmental stages. The resulting $P$-values were adjusted using the Benjamini and Hochberg's approach. Genes with an adjusted $P$-value $\leq 0.05$ and $\mid \log 2$ fold change $\mid \geq 1$ revealed by DESeq 2 were assigned as differentially expressed genes (DEGs).

\section{Weighted gene co-expression network analysis}

Weighted gene co-expression network analysis (WGCNA) was also used to evaluate gene expression. The WGCNA R package [108] was used to appraise modules of correlated genes and to investigate intramodular hub genes [109]. The eigengene value of each module was evaluated to examine the association with each gene [110]. The hub genes of each model were verified by calculating the connectivity degree (number of neighbors) of each gene with Cytoscape v3.6.1 [111]. The eigengene value of each module was calculated to test the association with each tissue type. The hub genes were defined by $\mathrm{kME}>1$, which measures a gene's connectivity in the specific module. To further identify those modules, GO and KEGG enrichment analyses were performed with the ClusterProfiler package [112]. 


\section{Quantitative real-time PCR}

To confirm the DEG and hub gene results in the RNAsequencing data, 14 DEGs and one hub gene were selected for further RT-qPCR measurement on a Bio-Rad realtime PCR system (CFX96 Touch, USA) using a TransStart Top Green qPCR SuperMix kit (Transgen, Beijing China). Total RNA was isolated from 'Kyoho' grape berries in the treatment and control groups using an RNAprep Pure Plant Kit (Polysaccharides \& Polyphenolics rich, DP441; Tiangen, Beijing, China) according to the manufacturer's instructions. The RNA was extracted from whole berries without the seeds. The berries, $0.5 \mathrm{~g}$, were ground, and $0.1 \mathrm{~g}$ of tissue was used for each extraction. The experimental method was according to the manufacturer's instructions. RNA integrity was evaluated with an RNA Nano 6000 Assay Kit using a Bioanalyzer 2100 system (Agilent Technologies, CA, USA). A HiScript II 1st Strand cDNA Synthesis Kit (R211-01; Vazyme, Nanjing, China) was used for reverse transcription. The reverse transcription was performed at $25^{\circ} \mathrm{C}$ for $5 \mathrm{~min}, 52^{\circ} \mathrm{C}$ for $15 \mathrm{~min}$, and $85^{\circ} \mathrm{C}$ for $5 \mathrm{~min}$. The primers of the 15 genes were constructed using Primer Premier 5.0 software, and the sequences are provided in Supplemental Table S4. The suitable reverse-transcribed cDNA was used as the template for RT-qPCR measurement. The reaction was performed in $10-\mu \mathrm{L}$ assays that contained $1 \mu \mathrm{L}$ of cDNA, $5 \mu \mathrm{L}$ of $2 \times$ Trans Start $^{\circ}$ Top Green qPCR SuperMix, $0.3 \mu \mathrm{L}$ of each primer, and $3.4 \mu \mathrm{L}$ of added double-distilled water. Reactions were performed in 40 cycles of $94{ }^{\circ} \mathrm{C}$ for $30 \mathrm{~s}$, $94{ }^{\circ} \mathrm{C}$ for $5 \mathrm{~s}$, and $60^{\circ} \mathrm{C}$ for $30 \mathrm{~s}$. Three biological and technical replicates were analyzed for each sample. The ubiquitin gene served as the reference gene. All analyses included three independent biological replicates. The relative expression levels of the target genes were calculated using the $2^{-\Delta \Delta C T}$ approach [113].

\section{Statistical analyses}

The RT-qPCR results of the 15 genes at single time points were compared by one-way ANOVA followed by a Tukey's HSD post-hoc test with SPSS software (21.0 version, IBM Corp., NY, USA). Data are presented as means \pm SD. The asterisk (*) stands for the levels of significant difference (" $p$ value $\leq 0.05,{ }^{* *} p$ value $\left.\leq 0.01\right)$.

\section{Supplementary Information}

The online version contains supplementary material available at https://doi. org/10.1186/s12864-020-07180-y.

Additional file 1: Supplemental Table S1. Data overview of the transcriptome sequencing.

Additional file 2: Supplemental Table S2. The gene number and gene annotation information of DEGs from the comparison of $\mathrm{H} 4-\mathrm{K} 4$ stage.

Additional file 3: Supplemental Table S3. The node genes and hub gene annotation from the WGCNA analysis shown in Fig. 7.
Additional file 4: Supplemental Table S4. Primers used for

quantitative PCR analysis in this study.

Additional file 5: Supplemental Table S5. The numerical outputs of qRT-PCR with Tukey's HSD post hoc test. The asterisk $\left(^{*}\right)$ and bold values stands for the levels of significant difference $\left({ }^{*} p\right.$ value $\leq 0.05,{ }^{* *} p$ value $\leq$ 0.01).

Additional file 6: Supplemental Figure S1. Grouping optimization of gene expression patterns for TC-seq analysis based on Calinski criterion value.

Additional file 7: Supplemental Figure S2. Cytoscape representation of co-expressed genes with edge weight $\geq 0.10$. The important hub gene was noted with yellow. a The hub gene of $\mathrm{H} 1$ stage; $\mathbf{b}$ The hub gene of K1 stage; c The hub gene of K3 stage; $\mathbf{d}$ The hub gene of K4 stage, respectively.

Additional file 8: Supplemental Figure S3. Correlation between the gene expression ratios obtained from RNA-seq data and qRT-PCR. The $x$ axis indicates the $\log 2$ transformed FPKM of genes at different development stages. The $y$-axis represents the log2 transformed expression of genes at different development stages.

Additional file 9: Supplemental Figure S4. Scattergram of both GO enrichment analysis and KEGG pathways analysis. The X-axis indicates the berry development stages; the Y-axis indicates the GO terms or KEGG pathway. a GO enrichment analysis of WGCNA; b KEGG pathway analysis of WGCNA. Coloring indicates q-value with higher in red and lower in blue. And the lower q-value indicates the more significantly enriched. Point size indicates genes number.

\section{Abbreviations}

CAB: Chlorophyll a-b binding protein; COG: Clusters of Orthologous Groups; DEGs: Differentially expressed genes; dpa: Days post anthesis;

FPKM: Fragments Per Kilobase per Million; GLIP: GDSL esterase/lipase; GSTF12: Glutathione S-transferase F12; GO: Gene Ontology; $\mathrm{H}_{2} \mathrm{O}_{2}$ : Hydrogen peroxide; HSP: Heat shock protein; KEGG: Kyoto Encyclopedia of Genes and Genomes; KOG: Karyotic Orthologous Groups; LAC14: Laccase-14; $\mathrm{O}_{2}^{-}$

: Superoxide anion; OMT1: Caffeic acid 3-O-Methyltransferase; PAP15: Purple acid phosphatase; PCA: Principal component analysis; PCD: Programmed cell death; PSII: Photosystem II; PSA: Photosystem I reaction center subunit II; qRT-PCR: quantitative real-time reverse transcription PCR; RNA-seq: RNAsequencing; ROS: Reactive oxygen species; TCseq: Time Course sequencing; WGCNA: Weighted gene co-expression network analysis; XTH30: Xyloglucan endotransglucosylase/hydrolase protein 30

\section{Acknowledgments}

We thank Huili Zhao for her excellent technical assistance and all members of the Guo laboratory for their helpful discussions.

\section{Authors' contributions}

Conceptualization, D.-L.G. and Z.-G.W.; Methodology and Experimentation, L.L.G. and Z.-G.W.; Data Curation, L.-L.G. and Z.-G.W.; Writing Original Draft Preparation, D.-L.G, and Z.-G.W.; Writing-Review\& Editing, D.-L.G, Y.-H.Y. and M.-S.P. Supervision, D.-L.G. All authors read and approved the final manuscript.

\section{Funding}

This work was supported by Zhongyuan Science Technology Innovation Leaders (194200510007), National Natural Science Foundation of China (NSFC: 31672106, U1904113), National Key Research and Development Program of China (2018YFD1000105), Key R \& D and Promotion Projects in Henan Province (No. 202102110043). The funding bodies had no role in the design of the study, collection, analysis, or interpretation of data, or in writing the manuscript.

\section{Availability of data and materials}

The RNA-Seq data supporting the results of this article have been uploaded to the Sequence Read Archive of NCBI (National Center for Biotechnology Information). It could be accessed via the NCBI SRA database with accession numbers of PRJNA541089 from 5th May 2019 onwards. Until then, these 
sequences are available from the corresponding author upon reasonable request.

\section{Ethics approval and consent to participate}

Not applicable.

\section{Consent for publication}

Not applicable.

\section{Competing interests}

The authors declare that they have no competing interests.

\section{Received: 18 March 2020 Accepted: 22 October 2020}

Published online: 11 November 2020

\section{References}

1. Khadivi A, Gismondi A, Canini A. Genetic characterization of Iranian grapes (Vitis vinifera L.) and their relationships with Italian ecotypes. Agroforest. Syst. 2019;93(2):435-47.

2. Fasoli M, Richter CL, Zenoni S, Bertini E, Vitulo N, Dal Santo S, et al. Timing and order of the molecular events marking the onset of berry ripening in grapevine. Plant Physiol. 2018;178(3):1187-206.

3. Lijavetzky D, Carbonell-Bejerano P, Grimplet J, Bravo G, Flores P, Fenoll J, et al. Berry flesh and skin ripening features in vitis vinifera as assessed by transcriptional profiling. PLoS One. 2012;7(6):e39547.

4. Guo DL, Li Q, Zhao HL, Wang ZG, Zhang GH, Yu YH. The variation of berry development and DNA methylation after treatment with 5-azaC on 'Kyoho' grape. Sci Hortic. 2019;246:265-71.

5. Conde C, Silva P, Fontes N, Dias ACP, Tavares RM, Sousa MJ, et al. Biochemical changes throughout grape berry development and fruit and wine quality. Food. 2007;1:1-12.

6. López-Vidal O, Camejo D, Rivera-Cabrera F, Konigsberg M, Villa-Hernández JM, Mendoza-Espinoza JA, et al. Mitochondrial ascorbate-glutathione cycle and proteomic analysis of carbonylated proteins during tomato (Solanum Iycopersicum) fruit ripening. Food Chem. 2016:194:1064-72.

7. Jiménez A, Gómez JM, Navarro E, Sevilla F. Changes in the antioxidative systems in mitochondria during ripening of pepper fruits. Plant Physiol Biochem. 2002;40(6):515-20.

8. Guo LL, Xi FF, Yu YH, Wang ZG, Zhang GH, Guo DL. Studies of the riboflavin treatment for promoting the early ripening of 'Kyoho' grape berry. Hortic Sinica. 2017;44(10):1861-70.

9. Jimenez A, Creissen G, Kular B, Firmin J, Robinson S, Verhoeyen M, et al. Changes in oxidative processes and components of the antioxidant system during tomato fruit ripening. Planta. 2002;214(5):751-8.

10. Guo DL, Wang ZG, Li Q, Gu SC, Zhang GH, Yu YH. Hydrogen peroxide treatment promotes early ripening of Kyoho grape. Aust J Grape Wine R. 2019;25(3):357-62.

11. Foyer $\mathrm{CH}$, Lopez-Delgado H, Dat JF, Scott IM. Hydrogen peroxide- and glutathione-associated mechanisms of acclimatory stress tolerance and signalling. Physiol Plant. 1997;100:241-54.

12. Lin $Y X$, Lin YF, Chen YH, Hui W, Lin HT. Effects of hydrogen peroxide on quality of harvested longan fruits during storage. Food Sci. 2016;37(22):244-8.

13. Marinho HS, Real C, Cyrne L, Soares H, Antunes F. Hydrogen peroxide sensing, signaling and regulation of transcription factors. Redox Biol. 2014;2: 535-62.

14. Vavilala SL, Gawde KK, Sinha M, D'Souza JS. Programmed cell death is induced by hydrogen peroxide but not by excessive ionic stress of sodium chloride in the unicellular green alga Chlamydomonas reinhardtii. Eur J Phycol. 2015;50(4):422.

15. Chiriboga $M$, Giné Bordonaba J, Schotsmans WC, Larrigaudière C, Recasens I. Antioxidant potential of 'conference' pears during cold storage and shelf life in response to 1-methylcyclopr opene. LWT Food Sci Technol. 2013; 51(1):170-6

16. Pilati S, Brazzale D, Guella G, Milli A, Ruberti C, Biasioli F, et al. The onset of grapevine berry ripening is characterized by ROS accumulation and lipoxygenase-mediated membrane peroxidation in the skin. BMC Plant Biol. 2014;14(1):87.

17. Todd JF, Paliyath G, Thompson JE. Characteristics of a membrane-associated lipoxygenase in tomato fruit. Plant Physiol. 1990;94:1225-32.
18. Kumar V, Irfan M, Ghosh S, Chakraborty N, Chakraborty S, Datta A. Fruit ripening mutants reveal cell metabolism and redox state during ripening. Protoplasma. 2016;253(2):581-94.

19. Guo DL, Zhang GH. A new early-ripening grape cultivar- 'Fengzao'. Acta Hortic. 2015;1082:153-6.

20. Guo DL, Xi FF, Yu YH, Zhang XY, Zhang GH, Zhong GY. Comparative RNASeq profiling of berry development between table grape 'Kyoho' and its early-ripening mutant 'Fengzao'. BMC Genomics. 2016;17(1):795-811.

21. Xi FF, Guo LL, Yu YH, Wang Y, Li Q, Zhao HL, et al. Comparison of reactive oxygen species metabolism during grape berry development between 'Kyoho' and its early ripening bud mutant 'Fengzao'. Plant Physiol Biochem. 2017;118:634-42.

22. Wang ZG, Guo LL, Ji XR, Yu YH, Zhang GH, Guo DL. Transcriptional analysis of the early ripening of 'Kyoho' grape in response to the treatment of riboflavin. Genes. 2019;10(7):514.

23. Zou XY, Liu AY, Zhang Z, Ge Q, Fan SM, Gong WK, et al. Co-expression network analysis and hub gene selection for high-quality fiber in upland cotton (Gossypium hirsutum) using RNA sequencing analysis. Genes. 2019; 10(2):119.

24. Smoot ME, Ono K, Ruscheinski J, Wang PL, Ideker T. Cytoscape 2.8: new features for data integration and network visualization. Bioinformatics. 2011; 27(3):431-2

25. Kaur N, Dhawan M, Sharma I, Pati PK. Interdependency of reactive oxygen species generating and scavenging system in salt sensitive and salt tolerant cultivars of rice. BMC Plant Biol. 2016;16(1):131.

26. Saxena I, Srikanth $\mathrm{S}$, Chen Z. Cross talk between $\mathrm{H}_{2} \mathrm{O}_{2}$ and interacting signal molecules under plant stress response. Front Plant Sci. 2016;7:1-16.

27. Orabi SA, Dawood MG, Salman SR. Comparative study between the physiological role of hydrogen peroxide and salicylic acid in alleviating the harmful effect of low temperature on tomato plants grown under sandponic culture. Sci Agrár. 2015;9(1):49-59.

28. Jiang JJ, Zhu S, Yuan Y, Wang Y, Zeng L, Batley J, et al. Transcriptomic comparison between developing seeds of yellow- and black-seeded Brassica napus reveals that genes influence seed quality. BMC Plant Biol. 2019;19(1):203.

29. Socquet-Juglard D, Kamber T, Pothier JF, Christen D, Gessler C, Duffy B, et al. Comparative RNA-seq analysis of early-infected peach leaves by the invasive phytopathogen Xanthomonas arboricola pv. pruni. PLoS One. 2013;8(1): e54196.

30. Lin ZY, Wang YM, Xia H, Liang D. Effects of exogenous melatonin and abscisic acid on the antioxidant enzyme activities and photosynthetic pigment in 'summer black' grape under drought stress. Earth Environ Sci. 2019;295:120-5.

31. Zhang ZH, Rengel Z, Meney K, Pantelic L, Tomanovic R. Polynuclear aromatic hydrocarbons (PAHs) mediate cadmium toxicity to an emergent wetland species. J Hazard Mater. 2011;189(1-2):119-26.

32. Hasegawa PM, Bressan RA, Zhu JK, Bohnert HJ. Plant cellular and molecular responses to high salinity. Annu Rev Plant Biol. 2000;51(1):463-99.

33. Jia XM, Wang H, Svetla S, Zhu YF, Hu Y, Cheng L, et al. Comparative physiological responses and adaptive strategies of apple Malus halliana to salt, alkali and saline-alkali stress. Sci Hortic. 2019;245:154-62.

34. Guo R, Shi LX, Yan CR, Zhong XL, Gu FX, Liu Q, et al. lonomic and metabolic responses to neutral salt or alkaline salt stresses in maize (Zea mays L.) seedlings. BMC Plant Biol. 2017;17(1):41-54.

35. Fahnenstich $H$, Scarpeci TE, Valle EM, Flügge U, Maurino VG. Generation of hydrogen peroxide in chloroplasts of Arabidopsis overexpressing glycolate oxidase as an inducible system to study oxidative stress. Plant Physiol. 2008 . 148(2):719-29.

36. Lin $Y H$, Tan $L B$, Zhao $L$, Sun $X Y$, Sun CQ. RLS3, a protein with $A A A+$ domain localized in chloroplast, sustains leaf longevity in rice. J Integr Plant Biol. 2016:58(12):971-82.

37. Yu JJ, Chen S, Zhao Q, Wang T, Yang CP, Diaz C, et al. Physiological and proteomic analysis of salinity tolerance in Puccinellia tenuiflora. J Proteome Res. 2011;10(9):3852-70.

38. Steinhauser M, Steinhauser D, Koehl K, Carrari F, Gibon Y, Fernie AR, et al. Enzyme activity profiles during fruit development in tomato cultivars and solanum pennellii. Plant Physiol. 2010;153(1):80-98.

39. Eugène $P$, Ovaric $K J$, Jean $A$. Effects of calcium chloride treatment on the photosynthetic capacity and intensity of banana fruit during ripening. J Adv Biology Biotech. 2019;21(4):1-9. 
40. Cocaliadis MF, Fernández-Muñoz R, Pons C, Orzaez D, Granell A. Increasing tomato fruit quality by enhancing fruit chloroplast function. A doubleedged sword? J Exp Bot. 2013;65(16):4589-98.

41. Piechulla B, Glick RE, Bahl H, Melis A, Gruissem W. Changes in photosynthetic capacity and photosynthetic protein pattern during tomato fruit ripening. Plant Physiol. 1987;84(3):911-8.

42. Wang $H$, Schauer $N$, Usadel B, Frasse P, Zouine M, Hernould M, et al. Regulatory features underlying pollination-dependent and -independent tomato fruit set revealed by transcript and primary metabolite profiling. Plant Cell. 2009;21(5):1428-52.

43. Carrara S, Pardossi A, Soldatini G, Tognoni F, Guidi L. Photosynthetic activity of ripening tomato fruit. Photosyntheitica. 2001;39(1):75-8.

44. Yuan YJ, Xu X, Gong ZH, Tang YW, Wu MB, Yan F, et al. Auxin response factor $6 \mathrm{~A}$ regulates photosynthesis, sugar accumulation, and fruit development in tomato. Hortic Res. 2019;6(1):11-6.

45. Jansson S. The light-harvesting chlorophyll a /b-binding proteins. BBABioenergetics. 1994;1184:1-19.

46. Ma Q, Yang JL. Transcriptome profiling and identification of functional genes involved in $\mathrm{H}_{2} \mathrm{~S}$ response in grapevine tissue cultured plantlets. Genes Genom. 2018;40(12):1287-300.

47. Meng LH, Fan ZQ, Zhang Q, Wang CC, Gao Y, Deng YK, et al. BEL 1-LIKE HOMEODOMAIN 11 regulates chloroplast development and chlorophyll synthesis in tomato fruit. Plant J. 2018;94(6):1126-40.

48. Silva J, Kim Y, Sukweenadhi J, Rahimi S, Kwon W, Yang DC. Molecular characterization of 5 chlorophyll $a / b$-binding protein genes from Panax ginseng Meyer and their expression analysis during abiotic stresses. Photosynthetica. 2016:3(54):446-58.

49. Peralta DA, Araya A, Gomez-Casati DF, Busi MV. Over-expression of SINAL7 increases biomass and drought tolerance, and also delays senescence in Arabidopsis. J Biotechnol. 2018;281:11-21.

50. Liang D, Shen YQ, Ni ZY, Wang Q, Lei Z, Xu NQ, et al. Exogenous melatonin application delays senescence of kiwifruit leaves by regulating the antioxidant capacity and biosynthesis of flavonoids. Front Plant Sci. 2018;9: 426-40

51. Timperio AM, Egidi MG, Zolla L. Proteomics applied on plant abiotic stresses: role of heat shock proteins (HSP). J Proteome. 2008;71(4):391-411.

52. Driedonks N, Xu JM, Peters JL, Park S, Rieu I. Multi-level interactions between heat shock factors, heat shock proteins, and the redox system regulate acclimation to heat. Front Plant Sci. 2015;6:999-1008.

53. Gupta SC, Sharma A, Mishra M, Mishra RK, Chowdhuri DK. Heat shock proteins in toxicology: how close and how far? Life Sci. 2010;86(11-12):37784.

54. Hilton GR, Lioe H, Stengel F, Baldwin AJ, Benesch JLP. Small heat-shock proteins: paramedics of the cell. Top Curr Chem. 2013;328:69-98.

55. Chen B, Feder ME, Kang L. Evolution of heat-shock protein expression underlying adaptive responses to environmental stress. Mol Ecol. 2018; 27(15):3040-54

56. Sewelam N, Kazan K, Hüdig M, Maurino VG, Schenk PM. The AtHSP17.4C1 gene expression is mediated by diverse signals that link biotic and abiotic stress factors with ROS and can be a useful molecular marker for oxidative stress. Int. J Mol Sci. 2019;20(13):3201-18.

57. Neta-Sharir I, Isaacson T, Lurie S, Weiss D. Dual role for tomato heat shock protein 21: protecting photosystem II from oxidative stress and promoting color changes during fruit maturation. Plant Cell. 2005;17(6):1829-38.

58. Guo SJ, Zhou HY, Zhang XS, Li XG, Meng QW. Overexpression of CaHSP26 in transgenic tobacco alleviates photoinhibition of PSII and PSI during chilling stress under low irradiance. J Plant Physiol. 2007;164(2):126-36.

59. Ji XR, Yu YH, Ni PY, Zhang GH, Guo DL. Genome-wide identification of small heat-shock protein (HSP20) gene family in grape and expression profile during berry development. BMC Plant Biol. 2019;19(1):433.

60. Arce DP, Krsticevic FJ, Bertolaccini MR, Ezpeleta J, Ponce SD, Tapia E. Analysis of small heat shock protein gene family expression (RNA-Seq) during the tomato fruit maturation. IFMBE Proc. 2015;49:679-82.

61. Medina-Escobar N, Cardenas J, Munoz-Blanco J, Caballero JL. Cloning and molecular characterization of a strawberry fruit ripening-related cDNA corresponding a mRNA for a low-molecular-weight heat-shock protein. Plant Mol Biol. 1998;36(1):33-42.

62. Arce D, Spetale F, Krsticevic F, Cacchiarelli P, Las Rivas JD, Ponce S, et al. Regulatory motifs found in the small heat shock protein (SHSP) gene family in tomato. BMC Genomics. 2018;19(8):860.
63. Ramakrishna W, Deng Z, Ding C, Handa AK, Ozminkowski RH. A novel small heat shock protein gene, vis1, contributes to pectin depolymerization and juice viscosity in tomato fruit. Plant Physiol. 2003;131(2):725-35.

64. Faurobert M, Mihr C, Bertin N, Pawlowski T, Negroni L, Sommerer N, et al. Major proteome variations associated with cherry tomato pericarp development and ripening. Plant Physiol. 2007;143(3):1327-46.

65. Zhang N, Shi JW, Zhao HY, Jing J. Activation of small heat shock protein (SIHSP17.7) gene by cell wall invertase inhibitor (SICIF1) gene involved in sugar metabolism in tomato. Gene. 2018;679:90-9.

66. Li L, Wang XG, Zhang XH, Guo M, Liu TL. Unraveling the target genes of RIN transcription factor during tomato fruit ripening and softening. J Sci Food Agric. 2017;97(3):991-1000.

67. Mondal K, Malhotra SP, Jain V, Singh R. Oxidative stress and antioxidant systems in guava (Psidium guajava L.) fruits during ripening. Physiol Mol Biol Plants. 2009:15(4):327-34

68. Zimmermann P, Heinlein C, Orendi G, Zentgraf U. Senescence-specific regulation of catalases in Arabidopsis thaliana (L.) Heynh. Plant Cell Environ. 2006;29(6):1049-60.

69. Dhindsa RS, Plumb-Dhindsa P, Thorpe TA. Leaf senescence: correlated with increased levels of membrane permeability and lipid peroxidation, and decreased levels of superoxide dismutase and catalase. J Exp Bot. 1981;32: 93-101.

70. Jiang $X J$, Lin HT, Lin MS, Hui CY, Hui W, Xiong LY, et al. A novel chitosan formulation treatment induces disease resistance of harvested litchi fruit to Peronophythora litchii in association with ROS metabolism. Food Chem. 2018;66:299-308.

71. Sun J, You XR, Li L, Peng HX, Su WQ, Li CB, et al. Effects of a phospholipase $D$ inhibitor on postharvest enzymatic browning and oxidative stress of litchi fruit. Postharvest Biol Technol. 2011;62(3):288-94.

72. Tian SP, Qin GZ, Li BQ. Reactive oxygen species involved in regulating fruit senescence and fungal pathogenicity. Plant Mol Biol. 2013;82(6):593-602.

73. Chin CF, Teoh EY, Chee MJY, Al-Obaidi JR, Rahmad N, Lawson T. Comparative proteomic analysis on fruit ripening processes in two varieties of tropical mango (Mangifera indica). Protein J. 2019;38(6):704-15.

74. Xiang JH, Chen XB, Hu W, Xiang YC, Yan ML, Wang JM. Overexpressing heat-shock protein OsHSP50.2 improves drought tolerance in rice. Plant Cell Rep. 2018:37(11):1585-95.

75. Xu JY, Xue CC, Xue D, Zhao JM, Gai JY, Guo N, et al. Overexpression of $\mathrm{GmHsp90s,} \mathrm{a} \mathrm{heat} \mathrm{shock} \mathrm{protein} 90$ (Hsp90) gene family cloning from soybean, decrease damage of abiotic stresses in Arabidopsis thaliana. PLoS One. 2013;8(7):e69810.

76. Lai C, Huang LM, Chen LO, Chan M, Shaw J. Genome-wide analysis of GDSL-type esterases/lipases in Arabidopsis. Plant Mol Biol. 2017;95(2):181-97.

77. Volokita M, Rosilio-Brami T, Rivkin N, Zik M. Combining comparative sequence and genomic data to ascertain phylogenetic relationships and explore the evolution of the large GDSL-Lipase family in land plants. Mol Biol Evol. 2010;28(1):551-65.

78. Agee AE, Surpin M, Sohn EJ, Girke T, Rosado A, Kram BW, et al. Modified vacuole phenotype1 is an Arabidopsis myrosinase-associated protein involved in endomembrane protein trafficking. Plant Physiol. 2009;152(1): 120-32.

79. Chen MX, Xuan LJ, Wang Z, Zhou LH, Li ZL, Du X, et al. Transparent testa8 inhibits seed fatty acid accumulation by targeting several seed development regulators in Arabidopsis. Plant Physiol. 2014;165(2):905-16.

80. Huang LM, Lai CP, Chen LFO, Chan MT, Shaw JF. Arabidopsis SFAR4 is a novel GDSL-type esterase involved in fatty acid degradation and glucose tolerance. Bot Stud. 2015;56(1):33-45.

81. Zhang BC, Zhang LJ, Li F, Zhang DM, Liu XL, Wang H, et al. Control of secondary cell wall patterning involves xylan deacetylation by a GDSL esterase. Nature Plants. 2017;3(3):1-9.

82. Kikuta Y, Ueda H, Takahashi M, Mitsumori T, Yamada G, Sakamori K, et al. Identification and characterization of a GDSL lipase-like protein that catalyzes the ester-forming reaction for pyrethrin biosynthesis in Tanacetum cinerariifolium- a new target for plant protection. Plant J. 2012;71(2):183-93.

83. Lee DS, Kim BK, Kwon SJ, Jin HC, Park OK. Arabidopsis GDSL lipase 2 plays a role in pathogen defense via negative regulation of auxin signaling. Biochem Bioph Res Co. 2009;379(4):1038-42.

84. Gao MJ, Yin X, Yang WB, Lam SM, Tong XH, Liu JY, et al. GDSL lipases modulate immunity through lipid homeostasis in rice. PLoS Pathog. 2017; 13(11):e1006724 
85. Ni PY, Ji XR, Guo DL. Genome-wide identification, characterization, and expression analysis of GDSL-type esterases/lipases gene family in relation to grape berry ripening. Sci Hortic. 2020;264:109162.

86. Witasari LD, Huang FC, Hoffmann T, Rozhon W, Fry SC, Schwab W. Higher expression of the strawberry xyloglucan endotransglucosylase/hydrolase genes FVXTH9 and FVXTH6 accelerates fruit ripening. Plant J. 2019;100(6): 1237-53.

87. Park YB, Cosgrove DJ. Xyloglucan and its interactions with other components of the growing cell wall. Plant Cell Physiol. 2015;56(2):180-94.

88. Pauly M, Keegstra K. Biosynthesis of the plant cell wall matrix polysaccharide xyloglucan. Annu Rev Plant Biol. 2016;67(1):235-59.

89. Cheng GP, Duan XW, Jiang YM, Sun J, Yang SY, Yang B, et al. Modification of hemicellulose polysaccharides during ripening of postharvest banana fruit. Food Chem. 2009;115(1):43-7.

90. Morales-Quintana L, Beltrán D, Mendez-Yañez Á, Valenzuela-Riffo F, Herrera R, Moya-León MA. Characterization of FCXTH2, a novel xyloglucan endotransglycosylase/hydrolase enzyme of chilean strawberry with hydrolase activity. Int J Mol Sci. 2020;21(9):3380.

91. Minic Z, Jouanin L. Plant glycoside hydrolases involved in cell wall polysaccharide degradation. Plant Physiol Biochem. 2006;44(9):435-49.

92. Opazo MC, Lizana R, Stappung Y, Davis TM, Herrera R, Moya-León MA. XTHs from Fragaria vesca: genomic structure and transcriptomic analysis in ripening fruit and other tissues. BMC Genomics. 2017;18(1):852-63.

93. Zhang ML, Ma YQ, Horst WJ, Yang ZB. Spatial-temporal analysis of polyethylene glycol-reduced aluminium accumulation and xyloglucan endotransglucosylase action in root tips of common bean (Phaseolus vulgaris). Ann Bot-London. 2016;118(1):1-9.

94. Yun Z, Li TT, Gao HJ, Zhu H, Gupta VK, Jiang YM, et al. Integrated transcriptomic, proteomic, and metabolomics analysis reveals peel ripening of harvested banana under natural condition. Biomolecules. 2019;9(5):167.

95. Tilahun S, Choi HR, Kwon H, Park SM, Park DS, Jeong CS. Transcriptome analysis of 'Haegeum' gold kiwifruit following ethylene treatment to improve postharvest ripening quality. Agronomy. 2020;10(4):487

96. Shi YZ, Zhu XF, Miller JG, Gregson T, Zheng SJ, Fry SC. Distinct catalytic capacities of two aluminium-repressed Arabidopsis thaliana xyloglucan endotransglucosylase/hydrolases, XTH15 and XTH31, heterologously produced in Pichia. Phytochem. 2015;112:160-9.

97. Divol F, Vilaine F, Thibivilliers S, Kusiak C, Sauge MH, Dinant S. Involvement of the xyloglucan endotransglycosylase/hydrolases encoded by celery XTH1 and Arabidopsis XTH33 in the phloem response to aphids. Plant Cell Environ. 2007;30(2):187-201.

98. Yan JW, Huang Y, He H, Han T, Di PC, Sechet JL, et al. Xyloglucan endotransglucosylase-hydrolase 30 negatively affects salt tolerance in Arabidopsis. J Exp Bot. 2019;19(70):1-12.

99. Kim D, Langmead B, Salzberg SL. HISAT: a fast spliced aligner with low memory requirements. Nat Methods. 2015;12(4):357-60.

100. Apweiler R, Bairoch A, Wu CH, Barker WC, Boeckmann B, Ferro S, et al. UniProt: the universal protein knowledgebase. Nucleic Acids Res. 2004;32: D115-9.

101. Finn RD, Bateman A, Clements J, Coggill P, Eberhardt RY, Eddy SR, et al. Pfam: the protein families database. Nucleic Acids Res. 2013;42(D1):D222-30.

102. Young MD, Wakefield MJ, Smyth GK, Oshlack A. Gene ontology analysis for RNA-seq: accounting for selection bias. Genome Biol. 2010;11(2):R14.

103. Tatusov RL, Galperin MY, Natale DA, Koonin EV. The COG database: a tool for genome-scale analysis of protein functions and evolution. Nucleic Acids Res. 2000;28(1):33-6.

104. Koonin EV, Fedorova ND, Jackson JD, Jacobs AR, Krylov DM, Makarova KS, et al. A comprehensive evolutionary classification of proteins encoded in complete eukaryotic genomes. Genome Biol. 2004;5(2):R7.

105. Kanehisa M, Goto S, Kawashima S, Okuno Y, Hattori M. The KEGG resource for deciphering the genome. Nucleic Acids Res. 2004;32(90001):D277-80.

106. Jun M, Gu L. TCseq: time course sequencing data analysis; 2019. p. 1-8. https://rdrr.io/bioc/TCseq/f/inst/doc/TCseq.pdf.

107. Love Ml, Huber W, Anders S. Moderated estimation of fold change and dispersion for RNA-seq data with DESeq2. Genome Biol. 2014;15(12):1-21.

108. Langfelder P, Horvath S. WGCNA: an R package for weighted correlation network analysis. BMC Bioinform. 2008;9:559.

109. Ghan R, Petereit J, Tillett RL, Schlauch KA, Toubiana D, Fait A, et al. The common transcriptional subnetworks of the grape berry skin in the late stages of ripening. BMC Plant Biol. 2017;17(1):94.
110. Gao H, Wang Y, Li W, Gu Y, Lai Y, Bi Y, et al. Transcriptomic comparison reveals genetic variation potentially underlying seed developmental evolution of soybeans. J Exp Bot. 2018;69(21):5089-104.

111. Shannon P, Markiel A, Ozier O, Baliga NS, Wang JT, Ramage D, et al. Cytoscape: a software environment for integrated models of biomolecular interaction networks. Genome Res. 2003;13(11):2498-504.

112. Yu GC, Wang LG, Han YY, He QY. ClusterProfiler: an R package for comparing biological themes among gene clusters. OMICS. 2012;16(5):284-7.

113. Livak KJ, Schmittgen TD. Analysis of relative gene expression data using real-time quantitative PCR and the $2^{-\Delta \Delta C T}$ method. Methods. 2001;25(4): $402-8$.

\section{Publisher's Note}

Springer Nature remains neutral with regard to jurisdictional claims in published maps and institutional affiliations.
Ready to submit your research? Choose BMC and benefit from:

- fast, convenient online submission

- thorough peer review by experienced researchers in your field

- rapid publication on acceptance

- support for research data, including large and complex data types

- gold Open Access which fosters wider collaboration and increased citations

- maximum visibility for your research: over $100 \mathrm{M}$ website views per year

At BMC, research is always in progress.

Learn more biomedcentral.com/submissions 